\title{
1 An unsaturated hydro-mechanical modelling of two in-situ experiments in
}

\section{Callovo-Oxfordian argillite}

3

4 Robert Charlier ${ }^{1}$, Frédéric Collin ${ }^{1}$, Benoît Pardoen ${ }^{1}$, Jean Talandie ${ }^{2}$, Jean-Pol Radu ${ }^{1}$, Pierre

$5 \quad$ Gerard $^{1}$

6

71 Université de Liège, Département ArGEnCo

8 Chemin des Chevreuils 1

94000 Liège

10 Belgium

$11+3243669142$

12

2 Agence nationale pour la gestion des déchets radioactifs (ANDRA), France

14

15

Corresponding author: f.collin@ulg.ac.be

16

Abstract

18

The unsaturated behaviour of Callovo-Oxfordian argillite is investigated through the modelling of 2 in-situ experiments. The first test studies the influence of ventilation in a

21 gallery on the hydro-mechanical behaviour of the rock mass. The second test consists in a gas injection in the rock mass from an experimental borehole. A hydro-mechanical model is

23 described and used in the modelling of the experiments. A review of the main hydro-

24 mechanical parameters of argillite is presented. The numerical results highlight the need of a

25 flow boundary condition reproducing the fluid transfers between the surroundings and the 
rock mass. The influence of dissolved gas on the compressibility of the liquid phase is also emphasized.

Keywords: modelling, unsaturated behaviour, ventilation, gas migration, multi-physics coupling

\section{Introduction}

The long term management of radioactive waste is nowadays a crucial issue in several countries. The most often proposed solution is storage in deep and weak permeable geological layers. Owing to their good confining properties, argillaceous rocks constitute an ideal barrier for the insulation of high-activity and long lived radioactive waste disposal. Some underground research laboratories (URL) have been drilled in Europe in order to study the feasibility of such solutions, for instance in France in a thick layer of Callovo-Oxfordian argillite (Félix et al., 1996), in Belgium in Boom clay (Neerdael \& Boyazis, 1997) or in Switzerland in the Opalinus clay (Croisé et al., 2004).

The research programs in the different laboratories must allow the understanding and the characterization of the confining properties of argillaceous rocks. Moreover it has to show that the construction of such repository site and the operation phases due to the storage of radioactive wastes will not introduce pathways for radionuclide's migration through the host rock. For instance, the different thermo-hydro-mechanical solicitations occurring during the drilling and the operation phases affect the host rock, by the creation of a perturbed zone around the underground structure openings, where the geotechnical and hydro-geological 
1 properties are modified (Tsang et al., 2005; Blüming \& Konietzky, 2003; Bossart et al.,

2 2002). Such zones could alter the confining function of the host rock.

3 The understanding of the geomechanical behaviour of argillaceous rocks is thus a crucial

4 issue to ensure the feasibility of such repository solutions. In order to well understand the 5 geomechanical behaviour of argillaceous rocks and its coupling with the hydraulic and 6 thermal conditions, several laboratory experiments are thus performed on small argillaceous 7 rock samples. In parallel to these laboratory investigations, large scale in-situ tests are achieved in the underground laboratories in order to provide additional data on more complex 9 loading paths.

In this paper, we focus especially on the modelling of the unsaturated behaviour of argillaceous rocks through the modelling of two in-situ experiments. These experiments deal with the understanding of fluid flows mechanisms under unsaturated conditions, and its potential coupling with the mechanical behaviour. Both in-situ experiments are performed by Andra in the underground research laboratory of Bure (France), drilled in Callovo-Oxfordian argillite. The first experiment investigates the unsaturated features of argillite through a ventilation test performed in an experimental gallery (SDZ). The second one analyzes the impact of gas migration on the rock mass behaviour through gas injection test performed from an injection chamber set up in a small borehole (PGZ1). After a description of the experiments and the main experimental observations that have been obtained in section 2, a general framework for unsaturated porous media is proposed and described in section 3. A review of the hydro-mechanical characteristics of Callovo-Oxfordian argillite is then presented in section 4. This review is useful to determine the hydro-mechanical parameters used in the modelling of the two in-situ experiments. The section 5 is devoted to the numerical results, with an emphasis on the main developments that allow a good reproduction 
1 of the experimental observations by the numerical results, as for instance the expressions of

2 the boundary condition or the influence of some hydraulic parameters.

3

\section{Andra Underground research laboratory in Bure - In situ experiments}

The building of an Underground Research Laboratory (URL) by Andra began in 1999 in Bure on the border of the Meuse and Haute-Marne departments in eastern France (Delay et al., 2007). The laboratory has been drilled in a geological layer of Callovo-Oxfordian argillite at $490 \mathrm{~m}$ depth. In this paper, we will focus on two experiments that are performed in this laboratory. The first one (SDZ experiment) investigates the unsaturated behaviour of argillite through a ventilation test achieved in a large scale gallery, whilst the second one (PGZ1 experiment) studies the host rock behaviour when gas is injected from an experimental borehole.

\subsection{SDZ experiment}

\subsubsection{General description}

The first in-situ experiment (SDZ) is devoted to the characterization of the structure and the size of the excavated damaged zone (EDZ) according to the desaturation and possible resaturation induced by the evolution of the ventilation conditions imposed in an experimental gallery. The experimental zone is isolated to the GED experimental horizontal gallery through a $2 \mathrm{~m}$ long airlock. The test zone contains a first part without covering (with a length of 7.2 $\mathrm{m})$ and, at the end, another $5 \mathrm{~m}$ long zone with a concrete covering with a thickness of $20 \mathrm{~cm}$ and a thin impervious geotextile (Figure 1). 
2 During the test, ventilation is performed in the gallery. After 230 days of ventilation, the

3 airlock was closed and the ventilation thus stopped in the experimental zone. The relative

4 humidity in the GED zone evolves freely. The moisture exchanges between this zone and the

5 GED gallery could only occur through axial flows in the damaged zone developed around the

6 cavity wall.

7

The air relative humidity and the temperature in the experimental gallery are monitored before and after the airlock closure thanks to several sensors set up at the gallery wall (Figure 2). From $160^{\text {th }}$ day, measurements of the pore pressures inside the rock mass are performed through sensors (characterized by a range of measurements from 0 to $10 \mathrm{MPa}$ ) set up with different orientations and distances from the experimental zone (Figure 3). Moreover a geological survey of the zone without covering is performed after the excavation of the GED gallery in order to characterize the damaged zone. It highlights the cracking of the CallovoOxfordian argillite.

\subsubsection{Experimental observations}

In this paper, only the main experimental observations are presented. More complete results can be found in Cruchaudet et al. (2010). The geological survey of the damaged zone in the non-covering part of the GED experiment is firstly performed thanks to 12 boreholes drilled in different directions from the gallery wall. The analysis of the fracturing in the damaged zone observed along different argillite cores shows that the vertical extent of the damaged zone $(1.5 \mathrm{~m})$ is higher than the horizontal one $(0.3 \mathrm{~m})$. The cracks density is also more important in the vertical direction. From a modelling point of view, an anisotropic mechanical 
1 behaviour (or at least an anisotropic initial stress state in the rock mass) is certainly needed to

2 explain these observations.

4 Moreover the development of the excavated damaged zone alters probably the permeability 5 near the GED gallery wall. Figure 4 (a) shows indeed that the pore pressures in a $3 \mathrm{~m}$ ring 6 around the non covering gallery are very low and close to the atmospheric pressure, whilst the 7 drainage has not a strong influence on the measurements of the sensors located from $4.5 \mathrm{~m}$ and $6 \mathrm{~m}$ to the cavity wall. Such distribution of the pore pressures around the gallery can be numerically reproduced if the permeability increases substantially in the damaged zone, in order to facilitate the drainage in this domain. Moreover the permeability seems to be not influenced in the far field (more than $4.5 \mathrm{~m}$ from the gallery), because the pore pressures are relative close to the initial water pressure in the rock mass. A hydro-mechanical coupling that provides an increase of the permeability with the argillite damage is certainly a way to interpret these experimental observations. On the other hand, the pore pressures in the borehole drilled horizontally at the end of the GED gallery are higher than the initial water pressure in the geological formation (4.5 MPa) (Figure 4 (b)). This increase of the pore pressures are characteristic to hydro-mechanical coupling induced by the anisotropic initial stress state and possibly an anisotropic mechanical model.

The analysis of the temporal evolution of the pore pressures in the non-covering zone is also

21 performed for different sensors located at the same distance from the gallery wall but in 22 boreholes drilled with different orientations (Figure 5). The results show that pore pressures are the highest when the dip of the borehole is $45^{\circ}$ according to the horizontal plane. On the other hand the pore pressures are the lowest in the boreholes drilled in the horizontal plane, with a perpendicular orientation to the GED gallery. Such observations illustrate that an initial 
1 anisotropy of the permeability has to be taken into account in addition to the development of

2 an excavated damage zone to explain this distribution of the pore pressures in the rock mass.

4 At the cavity wall, the pore pressures are first reduced by the drainage, before vapour 5 exchanges occur. In a second stage, the pore pressures are therefore progressively decreased 6 to the values corresponding to the air relative humidity (according to Kelvin's law). In the 7 SDZ experiment, owing to the interruption of the ventilation, the air relative humidity in the experimental zone is quite low after the closure of the airlock (around $50 \%$ ) (Figure 2),

9 which corresponds to a capillary pressure of about $90 \mathrm{MPa}$. It is actually difficult to interpret if the pore pressures near the cavity wall are experimentally rapidly in equilibrium or not with the surrounding conditions (thanks to the vapour exchanges), because the sensors do not monitor negative pore pressures. Nevertheless, the measurements of the water content into the rock mass highlight the low desaturation of the rock mass in comparison with the imposed atmospheric conditions in the gallery. Moreover, it is well known that higher permeability is observed in the damaged zone around the cavity (Armand et al., 2007). So if low pore pressures were measured at the cavity wall, it should be observed also in the sensors located at a distance of 2 or $3 \mathrm{~m}$ from there. But even if these pore pressures are low, they remain higher than the atmospheric pressure (Figure 4 (a) et (b)) and the rock mass remains thus saturated in this zone. The vapour transfers between the surrounding air and the rock mass seem to be thus not so rapid. As a consequence, the use of a classical flow boundary condition 21 imposing at the wall the suction corresponding to the air relative humidity will probably not 22 allow the reproduction of the experimental data, because such condition assumes an instantaneous equilibrium between the atmosphere and argillite and induces significant vapour exchanges. A better representation of the fluid exchanges at the gallery wall must be 
1 certainly considered. Taking into account the presence of a boundary layer where the rock-

2 atmosphere exchanges take place is a way to model such experiment.

2.2.PGZ1 experiment description

\subsubsection{General description}

The second in-situ experiment (PGZ1) is devoted to the characterization of the gas transfer properties of Callovo-Oxfordian argillite thanks to a gas injection test performed from an experimental borehole. This experiment takes place in the research laboratory of Bure between the GED and GEX horizontal galleries that are parallel experimental galleries spaced by $25 \mathrm{~m}$.

From the GED gallery, two $28 \mathrm{~m}$ long parallel and downward borehole are drilled with a dip of $35^{\circ}$ to the horizontal plane and a strike perpendicular to the GED gallery axis (Figure 6). These two boreholes have a diameter of $76 \mathrm{~mm}$ and are composed by 3 intervals with pore pressures sensors separated by packers. The gas injection in argillite is performed from the central interval of the injection borehole. The other intervals are used to follow the pore pressures evolution in the rock mass.

A last $23 \mathrm{~m}$ long downward borehole is drilled from the end of the GEX gallery with the same strike as the GEX gallery one. The dip of this borehole is $47.8^{\circ}$ to the horizontal plane. Its diameter is $101.3 \mathrm{~mm}$. It is used for the monitoring of the displacements in argillite thanks to extensometers. The shortest distance between the extensometer borehole and the centre of the gas injection interval is equal to $1.132 \mathrm{~m}$. 
2 After the drilling of the boreholes, the system evolves first freely and a resaturation stage is observed. After 188 days, nitrogen is injected in the injection interval. The gas test is composed by different periods of controlled gas injection rate, interrupted by 'shut-in' phases when gas injection ceases (Figure 7).

\subsubsection{Experimental observations}

9 In this paper, we will just analyze the pore pressures evolution measured thanks to 6 sensors located in the different intervals of the injection and the measuring boreholes (Figure 6).

After the set up of the sensors, the pore pressures increase and reach the initial water pressure in the rock mass around 4.5 MPa (Figure 8). Two hydraulic tests (pulse tests) are then performed in the interval 1 of the injection borehole in order to characterize the permeability of the host rock. At the same time, a decreasing phase of the pressures is observed in the different sensors, in particular in the interval 1 of the injection borehole. A leakage problem can not explain this decrease, because this phenomenon is observed in the two boreholes. A potential explanation is the drainage induced by the extensometer borehole, located close to the injection and the measuring boreholes (1.19 $\mathrm{m}$ from interval 1 of the injection borehole). This borehole is indeed filled by concrete with a permeability around $10^{-16} \mathrm{~m}^{2}$. This 21 permeability is higher than the host rock one, so that such drainage is possible. This assumption has to be examined thanks to the modelling of the experiment.

24 When gas test begins with controlled nitrogen flow rate periods, interrupted by 'shut-in' phases, an increase of the pore pressures is observed in the interval 1 of the injection 
1 borehole. The effect of the gas injection is not detected in the other intervals, except for the

2 central interval of the measuring borehole (interval 4) but with smaller magnitude (Figure 8

$3(\mathrm{c}))$.

3. General framework for unsaturated porous media

7 The modelling of the two in-situ experiments supposes the use of a hydro-mechanical model for unsaturated porous media. An advanced hydro-mechanical framework should be ideally developed, as anisotropic mechanical model or a model able to couple rock damage with permeability (Shao et al., 2006; Maleki \& Pouya, 2010; Arson \& Gatmiri, 2012). Nevertheless, the two large scale experiments highlight first and foremost fluid transfer processes in geomaterials. In a first modelling step, the change of the permeability induced by hydro-mechanical coupling in the damaged zone is therefore a priori imposed in our modelling. We focus thus mainly on the modelling of the water and gas flows in unsaturated porous media.

The balance equations are firstly recalled. Then the constitutive equations of the mechanical and the fluid transfers problems are described, with special emphasis on the different coupling existing between the mechanical and the hydraulic parts.

We assume that the geomaterials are porous media considered as the superposition of several continua (Coussy, 1995): the solid skeleton (grains assembly) and the fluid phases (liquid and gaseous phases). Hereafter the general framework is detailed for a binary fluid mixture composed by water and nitrogen, because nitrogen is the gas used in the PGZ1 experiment. The presence of air in the porous media is thus neglected. We consider that the liquid phase is composed by liquid water and dissolved nitrogen, whilst the gaseous phase is a mixture of water vapour and gaseous nitrogen. The balance equations and the constitutive relations can 
1 be nevertheless easily extended for other binary fluid mixtures of water and other gas species

2 (air, hydrogen, helium, argon...).

4 Based on averaging theories (Hassanizadeh \& Gray, 1979a, 1979b), Lewis and Schrefler 5 (2000) proposed the governing equations for the full dynamic behaviour of a partially 6 saturated porous medium. Hereafter these equations are presented for a general framework 7 where the gas pressure is assumed non constant. The equations are restricted for quasi-static 8 problem in unsaturated and isothermal conditions.

10 The unknowns of the mechanical and the flow problems are respectively the displacements $\underline{u}$, 11 the water pressure $p_{w}$ (possibly negative in unsaturated case) and the gas pressure $p_{g}$.

\subsection{Balance of momentum}

This equation corresponds to the equilibrium equation (Malvern, 1962). In the mixture balance of momentum equation, the interaction forces between fluid phases and grain skeleton cancels. This equation reads:

$$
\operatorname{div}(\underline{\underline{\sigma}})+\left(\rho_{s}(1-\phi)+S_{r, w} \rho_{w} \phi+\left(1-S_{r, w}\right) \rho_{g} \phi\right) \underline{g}=0
$$

where $\phi$ is the porosity, $\rho_{s}$ is the solid grain density, $\rho_{w}$ is the water density, $\rho_{g}$ is the gas gravity acceleration. 
2

3 Following the ideas of Panday \& Corapcioglu (1957) and Olivella et al. (1994), the fluid mass

4 balance equations are written for each chemical species (i.e. water and nitrogen). In this way

5 the terms related to the phase transfer cancel. The water and nitrogen mass balance equations

6 read:

7

8

9

10

11

12

13

14

15

16

17

18

19

20

21 In order to reproduce the stress-strain behaviour of partially saturated porous media, as the

$$
\underbrace{\operatorname{div}\left(\underline{f}_{w}\right)+\frac{\partial}{\partial t}\left(\rho_{w} \phi S_{r, w}\right)_{w}}_{\text {Liquid water }}+\underbrace{\operatorname{div}\left(\underline{f}_{v}\right)+\frac{\partial}{\partial t}\left(\rho_{v} \phi\left(1-S_{r, w}\right)\right)}_{\text {Water vapour }}-Q_{w}=0
$$

$$
\underbrace{\operatorname{div}\left(\underline{f}_{N_{2}}\right)+\frac{\partial}{\partial t}\left(\rho_{N_{2}} \phi\left(1-S_{r, w}\right)\right)}_{\text {Dry nitrogen in gaseous phase }}+\underbrace{\operatorname{div}\left(\underline{f}_{N_{2}-d}\right)+\frac{\partial}{\partial t}\left(\rho_{N_{2}-d} \phi S_{r, w}\right)}_{\text {Dissolved nitrogen in water }}-Q_{N_{2}}=0
$$

where $\rho_{v}, \rho_{N_{2}}$ and $\rho_{N_{2}-d}$ are the densities respectively of water vapour, nitrogen and dissolved nitrogen; $\underline{f}_{l}, \underline{f}_{v}, \underline{f}_{N_{2}}$ and $\underline{f}_{N_{2}-d}$ are the total mass flow respectively for liquid water, water vapour, nitrogen and dissolved nitrogen; $Q_{w}$ and $Q_{N_{2}}$ are the sink terms of water and nitrogen.

\subsection{Constitutive equations}

\subsubsection{Stress-strain behaviour}

shear strength or the collapse phenomena, two separates stress variables are needed. Different 
1 approaches exist (Nuth \& Laloui, 2006; Sheng, 2010). We choose to use the suction $s$

$2\left(=p_{g}-p_{w}\right)$ and the Generalized effective stress $\underline{\underline{\sigma^{\prime}}}$ (Nuth and Laloui, 2008):

3

4

$$
\underline{\underline{\sigma}}=\underline{\underline{\sigma^{\prime}}}+\left(S_{r, w} p_{w}+\left(1-S_{r, w}\right) p_{g}\right) \underline{\underline{I}}
$$

6 with $\underset{\underline{I}}{=}$ the identity tensor.

8 Anisotropic mechanical model associated with 3D analysis should be considered to reproduce

9 the overpressures observed at the end of the gallery. However in a first modelling step, only 2D modelling is performed, which does not allow the reproduction of such observations. An

11 isotropic linear elastic-perfectly plastic model (with Van Eekelen yield surface) is therefore assumed to reproduce the mechanical behaviour of the porous media (Barnichon, 1998). A non-associated framework is considered to introduce the dilatation angle in the model (Table 1). It reads:

$$
F \equiv I I_{\hat{\sigma}}+m\left(I_{\sigma}-\frac{3 c}{\tan \varphi}\right)=0
$$

with $I_{\sigma}$ and $I I_{\hat{\sigma}}$ respectively the first and second stress invariants, $c$ the cohesion and $\varphi$ the friction angle.

3.3.2. Solid density variation

For the considered materials and stress levels around radioactive waste disposals, the solid grain deformability is no more negligible and the general Biot framework (Biot, 1941) is used 
1 to model the hydromechanical coupled terms. Following the ideas of Biot, Coussy (2004)

2 proposed a thermodynamical framework of the problem, which leads to the expression of the 3 porosity variation:

4

$$
\dot{\phi}=(b-\phi)\left[\frac{S_{r, w}}{k_{s}} \dot{p}_{w}+\frac{1-S_{r, w}}{k_{s}} \dot{p}_{g}+\frac{\dot{\Omega}}{\Omega}\right]
$$

where $b$ is the Biot coefficient, $\dot{\Omega} / \Omega=\dot{\varepsilon}_{V}$ the skeleton volumetric deformation rate and $k_{s}$ is the grain compressibility. The porosity variation is used in the fluid balance equations (Equations 2 and 3) in the computation of the storage term. It introduces a coupling term between the mechanical behaviour and the fluid transfers.

\subsubsection{Fluid transport constitutive equations}

A 2-phase flow model is considered for the description of the fluid transport processes. This model is comprised of a liquid phase, composed of liquid water and dissolved nitrogen and a gaseous phase, which is an ideal mixture of dry nitrogen and water vapour. The mass flows take into account the advection of each phase using the generalized Darcy's law and the diffusion of the components within each phase (Fick's law):

19

$$
\underline{f}_{w}=\rho_{w} \underline{q}_{l} \text { and } \underline{f}_{v}=\rho_{v} \underline{q}_{g}+\underline{i}_{v}
$$

$$
\underline{f}_{N_{2}}=\rho_{N_{2}} \underline{q}_{g}+\underline{i}_{N_{2}} \text { and } \underline{f}_{N_{2}-d}=\rho_{N_{2}-d} \underline{q}_{l}+\underline{i}_{N_{2}-d}
$$


1 with $\underline{q}_{l}$ and $\underline{q}_{g}$ the advective fluxes respectively of the liquid and the gaseous phases; $\underline{i}_{v}, \underline{i}_{N_{2}}$

2 and $\underline{i}_{N_{2}-d}$ the diffusion fluxes respectively for the water vapour, the dry nitrogen and the 3 dissolved nitrogen.

4

5 The advection of each phase is described by the generalized Darcy's law for unsaturated 6 cases:

7

$$
\underline{q}_{l}=-\frac{\underline{\underline{K}}_{w}^{s a t} k_{r, w}}{\mu_{w}}\left(\underline{\operatorname{grad}}\left(p_{w}\right)+g \rho_{w} \underline{\operatorname{grad}}(y)\right)
$$

$$
\underline{q}_{g}=-\frac{\underline{\underline{K}}_{g}^{d r y} k_{r, g}}{\mu_{g}}\left(\underline{\operatorname{grad}}\left(p_{g}\right)+g \rho_{g} \underline{\operatorname{grad}}(y)\right)
$$

12 where $\underline{\underline{K}}_{w}^{\text {sat }}$ and $\underline{\underline{K}}_{g}^{d r y}$ are respectively the water and gas permeabilities tensor in saturated and

13 dry conditions; $k_{r, w}$ and $k_{r, g}$ are the water and gas relative permeabilities; $\mu_{w}$ and $\mu_{g}$ are the 14 water and gas dynamic viscosities; $g$ the gravity acceleration and $y$ the vertical upward 15 directed coordinate.

16

17 The dynamic viscosity of the gaseous mixture depends on the dynamic viscosity of each component of the mixture:

19

$$
\mu_{g}=\frac{1}{\frac{\rho_{N_{2}}}{\rho_{g} \mu_{N_{2}}}+\frac{\rho_{v}}{\rho_{g} \mu_{v}}}
$$


1 The diffusion of the components within each phase reads (Fick's law):

2

3

$$
\underline{i}_{v}=-\phi\left(1-S_{r, w}\right) \tau D_{v / N_{2}} \rho_{g} \underline{\operatorname{grad}}\left(\frac{\rho_{v}}{\rho_{g}}\right)=-\underline{i}_{N_{2}}
$$

4

$$
\underline{i}_{N_{2}-d}=-\phi S_{r, w} \tau D_{N_{2}-d / w} \rho_{w} \underline{\operatorname{grad}}\left(\frac{\rho_{N_{2}-d}}{\rho_{w}}\right)
$$

7 where $D_{v / N_{2}}$ and $D_{N_{2}-d / w}$ are the diffusion coefficient respectively in the gaseous mixture dry

8 nitrogen - water vapour and for the dissolved nitrogen in water; $\tau$ is the tortuosity of the 9 porous medium.

3.3.4. Liquid density variation

The compressible fluid is assumed to respect the following relationship (Lewis and Schrefler,

14 2000). This predicts an increase of water density as a function of the water pressure, defining $15 \chi_{w}$ as the liquid water compressibility:

$$
\dot{\rho}_{w}=\rho_{w} \chi_{w} \dot{p}_{w}
$$

\subsubsection{Gas density variation}

21 For the gaseous mixture of dry nitrogen and water vapour, the ideal gas law is assumed. The equations of state of perfect gas (Clapeyron's equation) and Dalton's law applied to dry air, water vapour and moist air yield (Pollock, 1986; Gawin et al., 1996): 


$$
p_{N_{2}}=\frac{\rho_{N_{2}} R T}{M_{N_{2}}} \text { and } p_{v}=\frac{\rho_{v} R T}{M_{v}}
$$

$$
p_{g}=p_{N_{2}}+p_{v} \text { and } \rho_{g}=\rho_{N_{2}}+\rho_{v}
$$

with $p_{v}$ and $p_{N_{2}}$ the partial vapour and nitrogen pressures; $M_{N_{2}}$ and $M_{v}$ the molar mass respectively of the dry nitrogen and the water vapour.

11 3.4.1. Kelvin's law

12

13 It is assumed that the water vapour in porous media is always in equilibrium with the liquid 14 water. The corresponding equilibrium restriction equation is given by Kelvin's law for the 15 vapour concentration in the gaseous phase:

16

$$
R H=h_{r}=\frac{p_{v}}{p_{v 0}}=\exp \left(\frac{-s M_{v}}{R T \rho_{w}}\right)
$$

19 where $R H=h_{r}$ is the relative humidity, $p_{v 0}$ is the water vapour saturation pressure at the same temperature, $s$ is the suction, $R$ is the universal gas constant $(8.314 \mathrm{~J} /(\mathrm{mol} \mathrm{K}))$ and $T$ is the absolute temperature in Kelvin. 
1 The water vapour saturation pressure $p_{v 0}$ is the vapour pressure in equilibrium with liquid

2 water pressure if the capillary effects are not considered. The saturated vapour concentration

3 can be obtained by an empirical relationship proposed by Ewen et al. (1989):

4

$$
\frac{1}{\rho_{v 0}}=194,4 \exp \left(-0,06374(T-273)+0,1634 \cdot 10^{-3}(T-273)^{2}\right)
$$

7 for temperature range between $293 \mathrm{~K}$ and $331 \mathrm{~K}$.

The amount of dissolved nitrogen in the liquid phase is always in equilibrium and proportional with the quantity of dry nitrogen. The amount of dissolved nitrogen is given by Henry's law (Weast, 1971).

$$
\rho_{N_{2}-d}=H_{N_{2}}(T) \rho_{N_{2}}
$$

where $H_{N_{2}}$ is Henry's coefficient for dissolved nitrogen, depending on temperature and water pressure (Gawin \& Sanavia, 2009), although these influences are neglected in this paper.

19

\section{Hydro-mechanical parameters of Callovo-Oxfordian argillite}

22 The determination of hydro-mechanical parameters of Callovo-Oxfordian argillite is needed

23 for the modelling of large-scale unsaturated experiments. Before a synthesis of the main 
1 mechanical and hydraulic parameters available in the literature, the geological context met

2 around the underground research laboratory of Bure is shortly described.

\subsection{Geological context}

6 Callovo-Oxfordian argillite is part of the Paris Basin. This basin is filled with a thick

7 accumulation of Mesozoic and Cenozoic sediments. The sedimentary formations of the eastern Paris Basin where the underground laboratory zone has been drilled dip slightly to the West and the North-West, as a simple monocline. This comes from to the subsidence of the central part of the Paris Basin. At the underground laboratory scale, the low dip of the geological layers allows to assume that if an anisotropic behaviour of argillite is observed, the main orientations of anisotropy are located in the horizontal planes and along the vertical axis.

The studied formation corresponds to an indurated clay-rich formation, called argillite. It is formed of mixed-layered illite-smectite minerals dominated by illite (up to 45-50\%), kaolinite, and minor amounts of chlorite (Gaucher et al., 2004). The carbonate cements (25 $\%$ ), essentially micritic and thus of marine origin, contribute together with the high contents of clay minerals to the very low-permeability of this rock (Distinguin \& Lavanchy, 2007). The proportions of the different minerals evolve with the depth, but are given here for argillite coming from the depth of $-490 \mathrm{~m}$. It corresponds to the one of the underground research

21 laboratory of Bure. 
1 Table 1 presents some typical values of some basic properties of Callovo-Oxfordian argillite

2 and highlights the low porosity and the high strength of this material.

\subsection{Hydraulic parameters}

6 The hydraulic constitutive behaviour linking suction and degree of saturation (or water 7 content) plays an important role in the case of unsaturated soils: retention curve and 8 mechanical behaviour are in fact coupled. Changes in degree of saturation produce 9 mechanical effects whereas, in turn, soil deformation modifies the degree of saturation. On 10 the other hand, the fluid flows in unsaturated conditions are mainly controlled by flow 11 parameters as the permeabilities of the liquid phase $\underline{\underline{K}}_{w}$ and the gaseous phase $\underline{\underline{K}}_{g}$. These 12 permeabilities evolve with degree of saturation, through the water and gas relative 13 permeabilities relationships (Equations 9 and 10). Three important relationships have to be 14 thus precisely determined in order to obtain accurate numerical predictions of the hydromechanical behaviour of the rock mass:

16 - the retention curve;

$17 \quad-\quad$ the water permeability evolution with the degree of saturation;

$18 \quad-\quad$ the gas permeability evolution with the degree of saturation.

20 Numerous experimental data exist in the literature on this topic. A synthesis of these data is 21 proposed hereafter for Callovo-Oxfordian argillite. The emphasis is on the strong experimental scattering for some of these relationships. 
1 The main experimental studies that are used for the determination of the retention curve are based

2 on the saline solutions methods (Delage et al., 1998). A synthesis of some experimental data 3 available in literature for Callovo-Oxfordian argillite is presented on Table 2. It presents for each 4 experimental study the wetting or the drying paths imposed, the size of the samples and the 5 number of measurements performed. All these data are represented on Figure 9 (a), where the 6 degree of saturation is plotted against the suction.

8 Although a lot of experimental data are available for the retention curve, few experimental studies 9 investigate the behaviour close to the saturation (no data for suction lower than $2 \mathrm{MPa}$ ), that corresponds to the conditions generally met around the disposal cavities. It is indeed difficult to 11 impose precisely high degree of saturation. Moreover an important scattering of the experimental data is observed. It could be explained among other things by the hysteretic behaviour of the soils retention curves. Figure 9 (b) shows indeed that a hysteresis can be introduced according to the hydraulic process imposed to the sample. It is well known that the highest degrees of saturation are covered by a drying path, whilst the lowest ones are obtained on a wetting curve. It has to be added that most of the data are obtained on free volume sample. The effect of confining pressure on the retention curve is thus still not investigated in these experimental studies.

\subsubsection{Water permeability}

The relation between the water permeability and the degree of saturation is often deduced from the drying kinetics of samples submitted to evolutions of the surrounding air relative humidity (Fredlund \& Rahardjo, 1993). Figure 10 (a) presents the results of some experimental study investigating the water permeability evolution of undisturbed CallovoOxfordian argillite. The scattering of the experimental data is quite low, but the permeability of saturated samples can vary between two orders of magnitude. It can be explained by 
1 anisotropy of the permeability, as shown in Figure 10 (b). The permeability in the horizontal

2 plane is generally higher than the permeability along the vertical axis.

4 4.3.3. Gas permeability

6 The determination of the gas permeability according to the degree of saturation is generally

7 obtained by imposing a gas pressure gradient at both samples extremities. When the steady state conditions are obtained, the gas permeability can be deduced from the gas injection rate

9 if a Darcean flow is assumed.

Table 3 summarizes experimental studies on gas permeability of undisturbed Callovo-

Oxfordian argillite. The gas used during the test, the gas pressure gradient imposed at both faces of the sample, the confining pressure imposed, the samples size and the number of measurements are detailed. Figure 11 (a) plots the gas permeability against the degree of saturation, whatever the sample orientation. Zhang \& Rothfuchs (2004) have previously highlighted anisotropy of the gas permeability. This anisotropy has the same order of magnitude as the water permeability anisotropy (Figure 10 (b)). Davy et al. (2007) confirm this anisotropy of the gas water permeability on argillite, but they underline that the anisotropy seems to be higher in the low saturation domain.

On the other hand, an analysis of the water permeability in saturated conditions and the gas permeability in dried conditions shows the limits of the intrinsic permeability concept. Figure 11 (b) illustrates indeed that the gas permeability of argillite in dried conditions is about two orders of magnitude higher than the water permeability in saturated conditions. Other experimental studies confirm also that the concept of intrinsic permeability is not valid in 
1 argillaceous materials (Davy et al., 2007; Malinsky, 2009; Cariou et al., 2012), owing to the

2 strong interactions that exist between the fluid and the porous media and that can modify the

3 microstructure of the material. For these reasons, we have introduce in our flow equations a

4 water permeability in saturated conditions $K_{w}^{\text {sat }}$ and a gas permeability in dried conditions

$5 \quad K_{g}^{\text {sec }}$ instead of an intrinsic permeability (Equations 9 and 10).

6 8

\section{Hydro-mechanical modelling of unsaturated field experiments}

In this section, the modelling of two in-situ experiments (SDZ and PGZ1) performed in the underground laboratory of Bure is presented. A general description of the experiments has been detailed in the section 2 . The modellings are performed with the finite element code Lagamine developed at University of Liege (Collin et al., 2002). The purpose of this section is not devoted to a full description of the numerical results, but rather on the emphasis on the main concepts that must be considered in the modelling of the unsaturated behaviour of argillite. Moreover the influence of some modelling choices on the numerical results is highlighted.

\subsection{Ventilation test - SDZ}

Hydro-mechanical numerical modelling is performed in order to obtain a better understanding of argillite behaviour and transfers occurring during the in situ ventilation test SDZ. The general hydro-mechanical framework proposed in section 3 is considered, which allows adopting an anisotropic initial stress state and permeability in argillite. The increase of the permeability induced by the hydro-mechanical coupling in the damaged zone is a priori imposed through an elliptic zone around the cavity, whose the dimensions are reproduced by 
1 the results of hydro-mechanical modelling and where the permeability is higher than in the

2 undisturbed argillite.

3 The question of the flow boundary condition imposed at the tunnel wall is first considered.

4 The boundary value problem is then described, before a presentation of the numerical results.

$6 \quad$ 5.1.1. Flow boundary condition

8 To reproduce the vapour flows occurring at the gallery wall, a classical approach consists to

9 impose the suction corresponding to the air relative humidity at the cavity wall (Jia et al., 10 2008). Such condition assumes an instantaneous equilibrium between the rock mass and the 11 surrounding air, which is probably too optimistic. The experimental observations have indeed 12 shown that the pore pressures in the different sensors remain high, whereas the air relative humidity in the gallery is relatively low.

A non classical boundary condition is thus proposed in order to reproduce better the water and vapour exchanges with the surroundings. In the new flow boundary condition, the total water flow is expressed as the sum of a vapour exchange condition $\bar{q}$ and a seepage flow $\bar{S}$ (Gerard et al., 2008):

$$
\bar{E}=\bar{q}+\bar{S}
$$

The vapour exchanges are built on the existence of a boundary layer on the cavity porous surface, where the transfers take place (Ghezzehei et al., 2004; Pintado et al., 2009). The exchanges are proportional to the difference of vapour densities between the cavity wall and the surrounding air. They are controlled by a mass transfer coefficient $\alpha$ : 


$$
\bar{q}=\alpha\left(\rho_{v}^{\Gamma}-\rho_{v}^{a i r}\right)
$$

4 with $\rho_{v}^{\Gamma}$ and $\rho_{v}^{\text {air }}$ the vapour densities respectively at the cavity wall and in the surrounding

5 air. The determination of the transfer coefficient could be achieved through drying tests

6 (Gerard et al., 2010), but in this paper this parameter will be calibrated to match the 7 experimental results.

9 The seepage flow contribution allows the drainage, as it also avoids unphysical liquid water flow from the gallery to the rock mass that are numerically observed in highly dilatant 11 materials when the atmospheric pressure is imposed at the cavity wall (Gerard et al., 2008). Liquid water flow occurs therefore if pore water pressure in the gallery wall rock is larger than the cavity air pressure. The seepage is thus a unilateral condition, introduced in a finite element code by a ramp function (Bardet \& Tobita, 2002; Zheng et al., 2009):

$$
\begin{cases}\bar{S}=K^{p e n}\left(p_{w}^{\Gamma}-p_{a t m}\right)^{2} & \text { if } p_{w}^{\Gamma} \geq p_{w}^{a i r} \text { and } p_{w}^{\Gamma} \geq p_{a t m} \\ \bar{S}=0 & \text { otherwise }\end{cases}
$$

with $K^{p e n}$ a penalty coefficient, $p_{w}^{\Gamma}$ and $p_{w}^{a i r}$ the water pressures respectively at the cavity wall and corresponding to the surrounding air relative humidity and $p_{a t m}$ the atmospheric pressure.

To introduce such flow boundary condition in a finite element code, classical quadrilateral 2D finite elements are needed, associated with a new boundary finite element through which the hydraulic exchanges take place (Gerard et al., 2008). A reduced integration scheme is used in 
1 the 2D element in order to avoid shear-locking. The special hydraulic boundary condition is

2 defined by four nodes (Figure 12). The first three nodes are located on the boundary (N1, N2

3 and N3). They allow a spatial discretization of the water pressure distribution along the

4 boundary. The fourth node (N4) is introduced to define the relative humidity of the

5 surroundings (as far as they correspond to the d.o.f. of the fourth node). Its geometrical

6 position does not influence the results. This fourth node is helpful for the modelling of the

7 relative humidity evolution in the experimental zone. Two Gauss points are considered for the

8 boundary finite element. The hydraulic flow is computed thanks to Equation (20), where the

9 vapor density of the surrounding air is computed at the fourth node and the vapor at the cavity

10 wall is evaluated at the Gauss points. More details on the numerical formulation of the

11 boundary finite element can be found in Gerard et al. (2008).

12

13 This flow boundary condition has been already tested for the modeling of drying tests

14 performed at the laboratory scale on soil samples (Gerard et al., 2010). In this paper, the

15 relevance of such a flow boundary condition is first highlighted at a large-scale with the

16 modeling of an in-situ ventilation experiment.

17

5.1.2. Boundary value problem

A 2D plane strain hydro-mechanical modelling of the SDZ experiment is performed. The

21 section of the tunnel is chosen in the non covering zone (Figure 1), where most of the 22 experimental data are available (Figure 3). The geometry of the problem is given on Figure 23 13. An elliptic excavated damage zone is considered, whilst the outer limits of the model are 24 located to $200 \mathrm{~m}$ from the centre of the gallery. The initial conditions in argillite are a 25 homogeneous water pressure of $4.5 \mathrm{MPa}$. An anisotropic initial stress state 
$1 \quad\left(\sigma_{h, 0}=\sigma_{v, 0}=12.0 \mathrm{MPa}-\sigma_{H, 0}=1.3 \sigma_{v, 0}=15.6 \mathrm{MPa}\right)$ is considered with the GED gallery axis

2 oriented with the same direction as the minor main horizontal stress. In this problem, the gas

3 flow problem is not solved and the gas pressure remains constant at the atmospheric pressure.

4 Isothermal conditions are considered $\left(T=298^{\circ} \mathrm{K}\right)$, because the temperatures remain relatively

5 constant after the closure of the airlock.

7 The boundary conditions at the gallery wall are summarized in Table 4. The GED gallery is 8 first drilled during 10 days. This first step is only considered in the hydro-mechanical model,

9 where the radial stress at the cavity wall $\sigma_{r}^{\Gamma}$ and the water pressure at the environmental node $p_{w}^{a i r}$ (corresponding to the surroundings) are progressively decreased to the atmospheric 11 pressure. 36 days after the end of the drilling, the set up of the concrete floor is achieved. The closure of the airlock is performed after 240 days, but this last step does not modify the boundary value problem. At the end of the drilling, the argillite - atmosphere interactions are modelled by imposing at the environmental node the water pressure corresponding to the air relative humidity measured into the gallery (Figure 2). Only the results from the operation phase to the end of the modelling are presented in this paper, which explains the negative time defined in Table 4 for the drilling step.

\subsubsection{Hydro-mechanical parameters}

21 The mechanical parameters of the different materials (undisturbed argillite, EDZ and concrete) used in the constitutive equations are presented in Table 5. No differences between undisturbed argillite and excavated damage zone are assumed from a mechanical point of

24 view. The main hydraulic characteristics are defined in Table 6. It must be noted that the permeability anisotropy ratio is equal to 3 , which corresponds to previous observations from 
1 Andra. Moreover the permeability is strongly increased in the excavated damage zone

2 (Armand et al., 2007). Even if it is known that the principal directions of anisotropy in the

3 damage zone do not correspond to the principal directions of the initial anisotropy (Bossart et

4 al., 2002), the same directions of anisotropy are considered. It could be justified by the large

5 increase of permeability in the damage zone and the low anisotropy ratio. The permeability in

6 the damage zone is almost homogeneous in comparison with the undisturbed argillite and the

7 principal directions do not influence the numerical results. To reproduce the unsaturated

8 behaviour of the rock mass, a retention curve and a water permeability curve are defined.

9 These relationships are based on the van Genuchten's equation (van Genuchten, 1980), with

10 parameters calibrated in order to reproduce at best the experimental data available (Figure 11 14):

$$
S_{r, w}=\left(1+\left(\frac{s}{P_{r}}\right)^{n}\right)^{\frac{1}{n}-1} \text { and } K_{w}=K_{w}^{s a t} k_{r, w}=K_{w}^{s a t} \sqrt{S_{r, w}}\left(1-\left(1-S_{r, w}^{1 / m}\right)^{m}\right)^{2}
$$

5.1.4. Numerical results

For the hydro-mechanical modelling of the SDZ ventilation test, the non classical flow boundary condition reproducing seepage and water exchanges at the cavity wall is taken into account. The mass transfer and the penalty coefficients defined in this relation (equations 21 and 22) are defined in Table 7. With the set of parameters for Callovo-Oxfordian argillite (Tables 5 and 6) and a good calibration of the mass transfer coefficient, good agreements between experimental observations and numerical results are obtained in terms of water pressures kinetic, both in the further and in the nearest zones (Figure 15). The anisotropy 24 behaviour observed in the pore pressures measurements is well reproduced. From a 
1 mechanical point of view, Figure 16 illustrates the yield index distribution around the gallery

2 at the end of the modelling (700 days). It shows that the anisotropy of the initial stress state is

3 sufficient to obtain an elliptic plastic zone around the GED gallery, as observed

4 experimentally. Moreover the extent of this domain corresponds to the one where fractures

5 are observed experimentally thanks to the core analysis (Table 8).

6

7 5.1.5. Discussion

9 In the modelling, a low value of the mass transfer coefficient is used, in comparison to coefficients determined on argillaceous materials samples during drying tests (Gerard et al., 2010). This low value provides a very low desaturation of argillite around the gallery. Owing to the good agreement obtained with the modelling, the water vapour exchanges at the gallery wall are not the most important transport mechanism. The ventilation has thus a small influence on the pore pressures distribution into the rock mass. Classical flow boundary condition imposing at the tunnel wall the suction corresponding to the surrounding air relative humidity does not allow a good reproduction of the hydraulic transfers between argillite and the surroundings, as shown in Figure 17. This last modelling shows the huge drainage in the excavated zone (Figure 17 (b)) due to the boundary condition imposed at the gallery wall, whilst the pore pressures are neither well reproduced in the undisturbed zone (Figure 17 (a)).

Even though the numerical results can be improved with a modification of characteristics of 21 the damage zone (extent, permeability...), it must be added that the predictions obtained with the non classical boundary condition are based on permeabilities values in agreement with those determined experimentally. The development of a non classical flow boundary condition is thus important in order to obtain correct numerical predictions and allows a physical explanation of the vapour exchanges at the cavity wall. 
2 On the other hand it exists a difference of order of magnitude between the mass transfer

3 coefficients used in the SDZ modelling $\left(10^{-5} \mathrm{~m} / \mathrm{s}\right)$ and the one determined experimentally

4 through drying tests $\left(10^{-2} \mathrm{~m} / \mathrm{s}\right)($ Gerard et al., 2010). A scale effect can possibly explain this

5 difference, but should be studied in depth.

7 Some discrepancies are nevertheless observed in boreholes 1 (horizontal) and 3 (vertical). It can be certainly improved by an accurate modelling of the hydro-mechanical coupling in the excavated damage zone. The extent and the permeability of the damage zone are indeed currently imposed at the beginning of the modelling, whereas the processes are more complex (Levasseur et al., 2009). The permeabilities are certainly not homogeneous in the damage zone. A coupling between permeability and strain can be a way to improve the numerical results (Levasseur et al., 2010).

The discrepancies can be also explained by some phenomena not currently reproduced in the modelling. For instance, 2D plane strain model does not allow the reproduction of the axial flows, which play certainly an important role in the damage zone when the airlock is closed. $2 \mathrm{D}$ axisymetrical or $3 \mathrm{D}$ modelling is therefore needed in order to reproduce more accurately the fluid transfers and improve the numerical results. On the other hand numerical water pressures higher than the initial ones are observed along borehole 3 (Figure 15 (c)). It can be explained by the anisotropy of the initial stress state, but these overpressures remain lower than the experimental ones observed at the end of the GED gallery (Figure 4 (b)). Considering an anisotropic mechanical model in a 3D modelling can certainly increase the agreement between the observations and the numerical results, among other things to reproduce the evolution of the damage zone extent along the GED gallery axis. 
4 The PGZ1 gas injection test is achieved in an inclined borehole drilled in Callovo-Oxfordian

5 argillite. A general description of the experiments has been detailed in the section 2 . The 6 purpose of this section is not devoted to a full description of the numerical results, but rather 7 on the emphasis of the main concepts that has to be considered in the modelling of gas 8 transport problems.

9

5.2.1. Boundary value problem

The gas injection borehole is an inclined borehole. Moreover argillite presents anisotropy of the permeability (already showed in the SDZ experiment modelling), which leads to perform a 3D modelling of the experiment. A half 3D mesh obtained by rotation around the axis of the injection borehole is considered. The injection interval (interval 1 on Figure 6) is modelled.

A hydraulic modelling of the problem is performed with the finite element code Lagamine. The drilling of the injection borehole followed by a period where the pore pressures evolved freely at the borehole wall are first modelled during 188 days. The gas problem is not solved during these two steps. The nitrogen injection is then modelled by imposing at one lateral face

21 of the injection interval the experimental gas flow (Figure 7). The numerical results of this 22 last period are presented hereafter. 
1 The main hydraulic characteristics of Callovo-Oxfordian argillite are presented in Table 9. It

2 must be noted that the permeability anisotropy ratio is equal to 3 , which corresponds to 3 previous observations from Andra. A continuous approach of the fluid flows is adopted, based

4 on the 2-phase flow model presented in the constitutive equations in the section 3 . To 5 reproduce these processes of fluid transport, a retention curve and a water and gas 6 permeabilities curves are defined. These relationships are based on the van Genuchten's 7 equations for the retention and the water permeability curves (equation 23), whilst a cubic law 8 is considered for the gas permeability curve:

9

$$
K_{g}=K_{g}^{d r y} k_{r, g}=K_{g}^{d r y}\left(1-S_{r, w}\right)^{3}
$$

The parameters of these relationships are presented in Table 9. They are calibrated in order to reproduce at best the experimental data available (Figure 14 and Figure 17).

In gas injection problems, it is necessary to model the progressive desaturation of the initially saturated injection interval with the gas conditions. In a hydro-mechanical framework for porous media, it leads to consider the injection interval as an equivalent porous media, with high permeability, porosity equal to 1 and a low air entry pressure. The parameters are also presented in Table 9.

\subsubsection{Numerical results}

The numerical results of the drilling phase followed by the increase of the pore pressures in the boreholes are not the purpose of this paper, but the modelling has shown that the drainage induced by the extensometer borehole could explain the decreasing trend of the pore pressures 
1 observed experimentally in the sensors located along the injection and measuring boreholes

2 and discussed in section 2 (Figures 6 and 8).

4 This section is thus only devoted to the hydraulic modelling of the gas injection test. The 5 experimental observations have shown that the pore pressures in intervals 2, 3, 5 and 6 are not 6 influenced by the nitrogen injection, but only by the drainage induced by the extensometer 7 borehole (Figure 8). We will focus on the numerical results obtained in interval 1, where the increase of the pore pressures is the most significant.

9

A first modelling with constant water compressibility $\left(\chi_{w}=510^{-10} \mathrm{~Pa}^{-1}\right)$ is performed. In this case, a sensitivity analysis of the argillite permeability achieved. Same water against gas permeabilities ratio is considered in the sensitivity analysis, and also a constant anisotropy ratio $K_{\text {hor }} / K_{\text {vert }}=3$. Figure 20 shows that the permeability of argillite controls mainly the trend 14 of the pore pressures at the end of the "shut-in" periods. Owing to the experimental observations, the water permeabilities presented in Table 9 are considered, because they match well the pore pressures at the end of the first two "shut-in" periods. The values of the pore pressures at the peaks are nevertheless not exactly reproduced.

On the other hand, argillite remains totally saturated during the gas injection (Figure 21). Water is indeed pressurized by gas injection, and the high air entry value of argillite avoids the desaturation of the host rock. The gas migration is thus controlled by the rate of dissolved nitrogen diffusion into water. The effects of a high concentration of dissolved gas on the fluid transfers must thus be considered carefully. An aspect generally neglected in hydromechanical model is the effect of solubility on the compressibility of the liquid phase. But in quasi or totally saturated media, the presence of dissolved air modifies the characteristics of 
1 the liquid phase. According to the development of Fredlund (1976), the compressibility of the

2 liquid phase $\chi_{l}$ can be expressed by:

$$
\chi_{l}=\chi_{w}+\frac{H_{N_{2}} B_{a w}}{p_{N_{2}}}
$$

6 with $\chi_{w}$ the water compressibility $\left(=510^{-10} \mathrm{~Pa}^{-1}\right), p_{N 2}$ the nitrogen partial pressure, $H_{N 2}$ the 7 Henry coefficient for nitrogen $(=0.0149)$ and $B_{a w}$ a pore pressure parameter defined by:

8

$$
B_{a w}=\frac{d p_{N_{2}}}{d p_{w}}
$$

This pore pressure parameter is equal to 1 at saturation and is always less than 1 otherwise. The compressibility due to the solution of nitrogen in water is approximately two orders of magnitude higher than the compressibility due to pure water. By introducing such relationships in our hydro-mechanical models, the numerical predictions present better agreement with the experimental pore pressures during the first three injection steps (Figure 22). The increase of compressibility in the injection interval provokes a decrease of the pore pressures at the peak, especially at the beginning of the gas injection when the partial nitrogen pressure is low and the influence of solubility on compressibility is thus significant.

\subsubsection{Discussion}

Even if some discrepancies appear after the third injection step, the introduction of the effect of the gas solubility on the compressibility of the liquid phase improves the agreement with the experimental observations during the first injection stages. The long-term gas injection 
1 features that are not well caught in the numerical analysis could be probably explained by

2 other processes that are not adopted in the boundary value problem or in the constitutive

3 equations. For instance, the introduction of a damaged zone around the boreholes, where the

4 geomechanical properties (permeability, air entry pressure) can be altered, should be relevant,

5 as shown in the modelling of the SDZ experiment (section 5.1). The effects of swelling

6 packers on the axial conductivity should be also introduced in the analysis. The modelling

7 shows also that the desaturation remains very low around the boreholes. Some transfer 8 parameters as the retention curve, the gas permeability or the diffusion coefficient are not well

9 known close to the saturation. An accurate determination of these parameters is needed to 10 reproduce the numerical predictions. Finally it is also well known that gas migration can be 11 associated with the development of localised dilatant pathways when the gas pressure 12 increases (Horseman et al. 1999, Harrington \& Horseman 2003, Marshall et al. 2005). Such observations are difficult to explain with standard porous medium flow models and suggest that a strong hydro-mechanical coupling is needed to adequately explain the formation and subsequent behaviour of gas conductive pathways. A way to reproduce these flow instabilities numerically is to introduce hydro-mechanical coupling between the pathways aperture,

17 permeability and air entry pressure, based on the ideas of the "embedded fracture model" (Olivella \& Alonso 2008; Gerard 2011; Gerard et al., 2012).

The introduction of all these features should be improved the numerical predictions of future simulations.

\section{Conclusions}

In this paper, the unsaturated behaviour of Callovo-Oxfordian argillite is investigated through two ins-situ experiments performed in the underground research laboratory of Bure. The first 
1 experiment studies the influence of the ventilation on the hydro-mechanical behaviour of the

2 host rock, especially on the structure and the characteristics of the damage zone observed

3 around the galleries. The second one examines the effects of gas migration in argillite.

This paper makes a contribution in the understanding of the unsaturated behaviour of argillite through hydro-mechanical modellings of the in-situ experiments. It constitutes also an overview on the main aspects to consider in the modelling of complex unsaturated problems.

9 The modelling of the ventilation test SDZ highlights the need of an accurate reproduction of the fluid transfers occurring between the rock mass and the surrounding air. The use of a nonclassical flow boundary condition based on the existence of a boundary layer is first tested on the modelling of a large-scale ventilation test. The numerical results show the relevance of such flow boundary conditions for the modelling of large-scale rock-atmosphere interactions problems. The first results shows the low vapour exchanges with the surroundings and the limits of classical boundary conditions that assume a instantaneous equilibrium between the surrounding air and the host rock. Moreover the plastic zone obtained with hydro-mechanical modelling corresponds to the zone where cracking are observed.

On the other hand, the 3D modelling of the gas migration test PGZ1 shows that an experiment designed initially to study the unsaturated features of the host rock is not necessary controlled by unsaturated characteristics of argillite. Diffusion of dissolved gas is in this test the main gas transfer mechanism. This paper investigates also the influence of dissolved gas on the compressibility of liquid phase. Such effect plays a significant role in totally saturated and quasi saturated porous media, whereas it is usually neglected in the hydro-mechanical models. 
2 A comparison of the two in-situ experiments modelling shows that the same water 3 permeabilities have been considered for undisturbed Callovo-Oxfordian argillite. A review of

4 the experimental data available for the retention curve and the water and gas relative 5 permeabilities is also presented for Callovo-Oxfordian argillite. Even though a large 6 dispersion of the experimental data is observed, the parameters used in the modellings are 7 consistent with this bibliographic analysis. This analysis could be significant in gas migration 8 problems if a low desaturation of the rock mass is induced by the gas injection around the

9 galleries. In this case, an accurate determination of the retention curve and the gas relative 10 permeability close to the saturation is needed in order to obtain reliable numerical results.

\section{Acknowledgments}

The authors would like to thank the FRS-FNRS and the European project FORGE for their financial support.

\section{References}

Andra, 2005. Projet HAVL - Dossier 2005. Référentiel site Meuse/Haute-Marne. Rapport Andra C.RP.ADS.04.0022.

Andra, 2009. Rapport mi-parcours pour le Groupement de Laboratoires "Transferts de Gaz". Rapport Andra C.RP.ASCM.09.0002, 242 p.

Armand, G., Wileveau, Y., Delay, J., 2007. Analyse des perméabilités mesurées autour des ouvrages du LSMHM au niveau -490 m pour déterminer des lois empiriques utilisables 
dans des calculs hydromécaniques couplés en milieu continu. Laboratoire de recherche souterrain de Meuse/Haute-Marne. Rapport Andra D.NT.ALS.07.0453, 27 p.

Arson, C., Gatmiri, B. 2012. Thermo-hydro-mechanical modeling of damage in unsaturated porous media: Theoretical framework and numerical study of the EDZ. International Journal for Numerical and Analytical Methods in Geomechanics. 36, 272-306.

Bardet, J.P., Tobita, T., 2002. A practical method for solving free-surface seepage problems. Comput. Geotech. 29, 451-475.

Barnichon, J.D., 1998. Finite element modelling in structural and petroleum geology. PhD. Thesis. Université de Liège, Belgium.

Biot, M.A., 1941. General theory of three-dimensional consolidation. J. Appl. Phys. 12, 155164.

Blüming, P., Konietzky, H., 2003. Development of an excavation disturbed zone in claystone, in: Natau, O., Fecker, S., Pimentel, S. (Eds.), Geotechnical measurements and modelling. Lisse, pp.127-32.

Bossart, P., Meier, P.M., Moeri, A., Trick, T., Mayor, J.C., 2002. Geological and hydraulic characterisation of the excavation disturbed zone in the Opalinus Clay of the Mont Terri Rock Laboratory. Eng. Geol. 66, 19-38.

Boulin, P.F., Angulo-Jaramillo, R., Daian, J.-F., Talandier, J., Berne, P., 2008a. Experiments to estimate gas intrusion in Callovo-oxfordian argillites. Phys. Chem. Earth. 33, S225S230.

Boulin, P.F., Angulo-Jaramillo, R., Daian, J.-F., Talandier, J., Berne, P., 2008b. Pore gas connectivity analysis in Callovo-Oxfordian argillite. Applied Clay Science. 42, 276-283.

Cariou, S., Skoczylas, F., Dormieux, L., 2012. Experimental measurements and water transfer models fort he drying of argillite. International Journal of Rock Mechanics \& Mining Sciences. 54, 56-69. 
1 Croisé, J., Schlickenrieder, L., Marschall, P., Boisson, J.Y., Vogel, P., Yamamoto, S., 2004. Hydrogeological investigations in a low permeability claystone formation: the Mont Terri Rock Laboratory. Phys. Chem. Earth. 29, 3-15.

Cruchaudet, M., Noiret, A., Talandier, J., Armand, G., 2010. Expérimentation SDZ - Bilan de la mise en place de l'instrumentation et des premières mesures à fin mars 2010 - Centre de Meuse - Haute-Marne. Rapport Andra D.RP.AMFS.09.0087.

Collin, F., Li, X.L., Radu, J.-P., Charlier, R., 2002. Thermo-hydro-mechanical coupling in clay barriers. Eng. Geol. 64, 179-193.

Coussy, O., 1995. Mechanics of Porous Continua. Wiley, London.

Coussy, O., 2004. Poromechanics. Wiley, London.

Davy, C.A., Skoczylas, F., Barnichon, J.-D., Lebon, P., 2007. Permeability of macro-cracked argillite under confinement: Gas and water testing. Phys. Chem. Earth. 32, 667-680.

Delage, P., Howat, M.D., Cui, Y.J., 1998. The relationship between suction and swelling properties in a heavily compacted unsaturated clay. Eng. Geol. 50, 31-48.

Delay, J., Vinsot, A., Krieguer, J.M., Rebours, H., Armand, G., 2007. Making of the underground scientific experimental programme at the Meuse/Haute-Marne underground research laboratory, North Eastern France. Phys. Chem. Earth. 32, 2-18.

Distinguin, M., Lavanchy, J.M., 2007. Determination of the hydraulic properties of the Callovo-Oxfordian Argillites at the Bure Site: synthesis of the results obtained in deep boreholes using several in-situ investigation techniques. Phys. Chem. Earth. 32, 379392.

Escoffier, S., Homand, F., Giraud, A., Hoteit, N., Su, K., 2005. Under stress permeability determination of the Meuse/Haute-Marne mudstone. Eng. Geol. 81, n³, 329-340.

Ewen, J., Thomas, H.R., 1989. Heating unsaturated medium sand. Géotechnique. 3, 455-470. 
1 Félix, B., Lebon, P., Miguez, R., Plas, F., 1996. A review of the ANDRA's research programmes on the thermo-hydromechanical behavior of clay in connection with the radioactive waste disposal project in deep geological formations. Eng. Geol. 41, 35-50.

François, B., Laloui, L., Laurent, C., 2009. Thermo-hydro-mechanical simulation of ATLAS in situ large scale test in Boom Clay. Comput. Geotech. 36, 626-640.

Fredlund, D.G., 1976. Density and compressibility characteristics of air-water mixtures. Can. Geotech. J. 13, 386-396.

Fredlund, D.G., Rahardjo, H., 1993. Soil mechanics for unsaturated soils. Wiley, New-York.

Gaucher, E., Robelin, C., Matray, J.M., Négrel, G., Gros, Y., Heitz, J.F., Vinsot, A., Rebours, H., Cassagnabère, A., Bouchet, A., 2004. Andra Underground research Laboratory : interpretation of the mineralogical and geochemical data acquired in the CallovianOxfordian formation by investigative drilling. Phys. Chem. Earth. 29, 55-77.

Gawin, D., Schrefler, B.A., 1996. Thermo-hydro-mechanical analysis of partially saturated porous materials. Eng. Computation. 13, nº7, 113-143.

Gawin, D., Sanavia, L., 2009. A unified approach to numerical modelling of fully and partially saturated porous materials by considering air dissolved in water. Computer Modeling in Engineering \& Sciences. 53, 255-302.

Gens, A., Vaunat, J., Garitte, B., Wileveau, Y., 2007. In situ behaviour of a stiff layered clay subjected to thermal loading: observations and interpretation. Géotechnique. $57, \mathrm{n}^{\circ} 2$, 207-228.

Gerard, P., Charlier, R., Chambon, R., Collin, F., 2008. Influence of evaporation and seepage on the convergence of a ventilated cavity. Water Resour. Research. 44, W00C02.

Gerard, P., Léonard, A., Masekanya, J.-P., Charlier, R., Collin, F., 2010. Study of soil-atmosphere moisture exchanges through convective drying tests in non-isothermal conditions. Int. J. Numer. Anal. Met.. 34, nº12, 1297-1320. 
1 Gerard, P., 2011. Impact des transferts de gaz sur le comportement poro-mécanique des matériaux argileux. PhD. Thesis. Université de Liège, Belgique.

3 Ghezzehei, T.A., Trautz, R.C., Finsterle, S., Cook, P.J., Ahlers, C.F., 2004. Modeling coupled evaporation and seepage in ventilated cavities. Vadose Zone J. 3, 806-818.

Harrington, J.F., Horseman, S.T., 2003. Gas migration in KBS-3 buffer bentonite. Sensitivity of test parameters to experimental boundary conditions. Technical Report SKB - TR-03$02,57 \mathrm{p}$.

Hassanizadeh, M., Gray, W., 1979a. General conservation equations for multi-phase systems: 1. Average procedure. Adv. Water Resour. 2, 131-144.

Hassanizadeh, M., Gray, W., 1979b. General conservation equations for multi-phase systems: 2. Mass, momenta, energy, and entropy equations. Adv. Water Resour. 2, 191-208.

Heitz, J.-F., Hicher, P.-Y., 2002. The mechanical behaviour of argillaceous rocks - Some questions from laboratory experiments, in : Hoteit, N., Su, K., Tijani, M., Shao J.-F. (Eds.), Hydromechanical and thermohydromechanical behaviour of deep argillaceous rock-theory and experiments. Taylor \& Francis, Paris, pp. 99-108.

Homand, F., Giraud, A., Escoffier, S., Koriche, A., Hoxha, D., 2004. Permeability determination of a deep argillite in saturated and partially saturated conditions. Int. J. Heat Mass Tran. 47, 3517-3531.

Horseman, S.T., Harrington, J.F., Sellin, P., 1999. Gas migration in clay barriers. Eng. Geol. $54,139-149$.

Hoxha, D., Auvray, D., 2005. Résultats des essais sur échantillons pour le développement des modèles rhéologiques HM et THM des argiles. Rapport Andra C.RPO.ENG 03.0380/D, $237 \mathrm{p}$. 
1 Jia, Y., Bian, H.B., Duveau, G., Su, K., Shao, J.F., 2008. Hydromechanical modelling of shaft excavation in Meuse/Haute-Marne laboratory. Physics and Chemistry of the Earth. 33, S422-S435.

Koriche, M.A., 2004. Caractérisation du comportement couplé des argilites de Meuse/HauteMarne aux états saturé et partiellement saturé. $\mathrm{PhD}$. Thesis. Département de Génie Civil-Hydrosystème-Géotechnique. Institut national polytechnique de Lorraine, Nancy, France.

Levasseur, S., Bésuelle, P., Collin, F., Chambon, R., Charlier, R., Viggiani, G., 2009. EDZ in clayey rocks : which effect on permeability? Proceedings of European Commission Timodaz-Teresa THMC conference, Luxemburg, Luxemburg, 29 Sept. - 01 Oct. 2009, $10 \mathrm{p}$.

Levasseur, S., Charlier, R., Frieg, B., Collin, F., 2010. Hydro-mechanical modelling of the excavation damaged zone around an underground excavation at Mont Terri Rock

Lewis, R.W., Schrefler, B.A., 2000. The Finite Element Method in the Static and Dynamic Deformation and Consolidation of Porous Media. Wiley, New York.

Maleki, K., Poya, A., 2010. Numerical simulation of damage-permeability relationship in brittle geomaterials. Computers and Geotechnics. 37(5), 619-628.

Malinsky, L., 2009. Etude expérimentale et modélisation du comportement hydro-mécanique

Malvern, L.E., 1969. Introduction tot the mechanics of a continuous medium. Prentice-Hall, $215 \mathrm{p}$. 
1 Marschall, P., Horseman, S.T., Gimmi, T., 2005. Characterisation of Gas Transport Properties of the Opalinus Clay, a Potential Host Rock Formation for Radioactive Waste Disposal. Oil Gas Sci. Technol. 60, 121-139.

Neerdael, B., Boyazis, J.P., 1997. The Belgium underground research facility: Status on the demonstration issues for radioactive disposal in clay. Nucl. Eng. Des. 176, 89-96.

Nuth, M., Laloui, L., 2008. Effective stress concept in unsaturated soils: Clarification and validation of a unified framework. Int. J. Numer. Anal. Met. 32, 771-801.

Olivella, S., Carrera, J., Gens, A., Alonso, E.E., 1994. Non isothermal multiphase flow of brine and gas through saline media. Transport Porous Med. 15, 271-293.

Olivella, S., Alonso, E.E., 2008. Gas flow through clay barriers. Géotechnique. 58, 157-168

Panday, S., Corapcioglu, M.Y., 1989. Reservoir transport equations by compositional approach. Transport Porous Med. 4, 369-393.

Pham, Q.T., 2006. Effet de la désaturation et de la resaturation sur l'argilite dans les ouvrages souterrains. PhD. Thesis. Ecole Polytechnique, France.

Pham, Q.T., Vales, F., Malinsky, L., Nguyen Minh, D., Gharbi, H., 2007. Effects of desaturation-resaturation on mudstone. Phys. Chem. Earth. 32, 646-655.

Pintado, X., Lloret, A., Romero, E., 2009. Assesment of the use of the vapour equilibrium technique in controlled-suction tests. Can. Geotech. J. 46, 411-423.

Pollock, D.W., 1986. Simulation of fluid flow and energy transport processes associated with high-level radioactive waste disposal in unsaturated alluvium. Water Resour. Research. $22,765-775$.

Semete, P., Imbert, C., Desgree, P., Février, B., Courtois, A., Touzé, G., 2008. Experimental study of the water permeability of a partially saturated argillite, in : Burlion, N., Rougelot, T. (Eds.), Thermo-Hydromechanical and Chemical Coupling in Geomaterials and Applications. Wiley, London, pp. 219-230. 
1 Shao, J.F., Duveau, G., Bourgeois, F., Chen, W.Z., 2006. Elastoplastic damage modeling in unsaturated rocks and applications. International Journal of Geomechanics. 6(2), 119130.

Sheng, D., 2010. Constitutive modelling of unsaturated soils : Discussion of fundamental principles, in Alonso, E.E., Gens, A. (Eds.), Unsaturated Soils. Taylor \& Francis, London, pp. 91-112.

Tsang, C.F., Stephansson, O., Hudson, J.A., 2000. A discussion of thermohydromechanical (THM) processes associated with nuclear waste repositories. Int. J. Rock Mech. Min. 37, 397-402.

Tsang, C.F., Bernier, F., Davis, C., 2005. Geohydromechanical processes in the Excavation Damaged Zone in crystalline rock, rock salt and indurated and plastic clays in the context of radioactive waste disposal. Int. J. Rock Mech. Min. 42, 109-125.

van Genuchten, M.T., 1980. A closed-form equation for predicting the hydraulic conductivity of unsaturated soils. Soil Sci. Soc. Am. J. 44, 892-898.

Volckaert, G., Ortiz, L., de Cannière, P., Put, M., Horseman, S.T., Harrington, J.F., Fioravante, V., Impey, M., 1995. MEGAS : Modelling and Experiments on Gas Migration in Repository Host Rocks - Phase 1 Final Report. European Commission Report EUR 16235 EN.

Weast, R.C., 1971. Handbook of Chemistry and Physics, 51th ed. CRC Press, Cleveland.

Wileveau, Y., Bernier, F., 2008. Similarities in the hydromechanical response of CallovoOxfordian clay and Boom Clay during gallery excavation. Phys. Chem. Earth 33, S343S349.

Yang, D., 2008. Caractérisation par la mesure de perméabilité au gaz de l'endommagement mécanique et hydrique dans l'EDZ des argilites du Callovo-Oxfordien. PhD. Thesis, Ecole des Mines de Paris, France, 208 p. 
1 Zhang, C., Rothfuchs, T., 2004. Experimental study of the hydro-mechanical behaviour of the

2 Callovo-Oxfordian argillite. Appl. Clay Sci. 26, 325-336.

3 Zhang, C., Rothfuchs, T., 2007. Laboratory experiments on the THM behaviour of clay rocks.

5 Zheng, H., Dai, H.C., Liu, D.F., 2009. A variational inequality formulation for unconfined seepage problems in porous media. Appl. Math. Model. 33, 437-450.

\begin{tabular}{|c|c|c|}
\hline Mechanical parameter & & Value \\
\hline Dry density & $\rho_{d}$ & $2.21-2.33 \mathrm{~g} / \mathrm{cm}^{3}$ \\
\hline Density & $\rho$ & $2.30-2.40 \mathrm{~g} / \mathrm{cm}^{3}$ \\
\hline Porosity & $\phi$ & $15-18 \%$ \\
\hline Water content & $w$ & $3-7 \%$ \\
\hline Young's modulus & $E$ & $4000-5600 \mathrm{MPa}$ \\
\hline Poisson's coefficient & $v$ & 0.3 \\
\hline Friction angle & $\varphi$ & $20-25^{\circ}$ \\
\hline Dilation angle & $\psi$ & $0^{\circ}$ \\
\hline Cohesion & $c$ & $3-7 \mathrm{MPa}$ \\
\hline Uniaxial compression strength & $\sigma_{c}$ & $20-30 \mathrm{MPa}$ \\
\hline Biot's coefficient & $b$ & 0.6 \\
\hline
\end{tabular}

Table 1: Geomechanical characteristics of Callovo-Oxfordian argillite (from Gens et al., 2007; Wileveau \&

\begin{tabular}{llll}
\hline Reference & Drying - wetting path & Sample size D-H & Measurements \\
\hline Andra (2009) LML & Drying - wetting & $20-10 \mathrm{~mm}$ & 30 \\
\hline Andra (2009) - Laego & Drying - wetting & $38-40 \mathrm{~mm}$ & 25 \\
\hline Hoxha \& Auvray (2005) & $?$ & $?$ & 6 \\
\hline Pham et al. (2007) & Drying - wetting & Hollow cylinder : $30 / 9-100 \mathrm{~mm}$ & 10 \\
\hline
\end{tabular}




\begin{tabular}{llll}
\hline Zhang \& Rothfuchs (2007) & Drying - wetting & $?$ & 31 \\
\hline Boulin et al. (2008a; 2008b) & Wetting & $80-2 \mathrm{~mm}$ & 26 \\
\hline Yang (2008) & Drying - wetting & $40-50 / 65 \mathrm{~mm}$ & 16
\end{tabular}

Table 2: Synthesis of experimental studies on retention behaviour of undisturbed Callovo-Oxfordian argillite

\begin{tabular}{lllllc}
\hline Reference & Gas & Pressure gradient & Confining pressure & Sample size D-H & Measurements \\
\hline Andra, 2009 (LML) & Argon & $1.8 \mathrm{MPa}$ & $5 \mathrm{MPa}$ & $37-10 \mathrm{~mm}$ & 25 \\
\hline Zhang \& Rothfuchs (2004) & Nitrogen & $1.9 \mathrm{MPa}$ & $2-16 \mathrm{MPa}$ & $40-80 \mathrm{~mm}$ & 17 \\
\hline Boulin et al. (2008b) & Helium & $0.2-2.5 \mathrm{MPa}$ & $9 \mathrm{MPa}$ & $?$ & 28 \\
\hline Yang (2008) & Argon & $2.5 \mathrm{MPa}$ & $5 \mathrm{MPa}$ & $40-50 / 65 \mathrm{~mm}$ & 10 \\
\hline
\end{tabular}

Table 3: Synthesis of experimental studies on gas permeability evolution with degree of saturation of

\begin{tabular}{|c|c|c|c|c|c|c|}
\hline \multirow{2}{*}{ Step } & \multirow{2}{*}{$\begin{array}{c}t_{\text {ini }} \\
\text { (days) }\end{array}$} & \multirow{2}{*}{$\begin{array}{c}t_{f i n} \\
\text { (days) }\end{array}$} & \multicolumn{2}{|c|}{ Water exchanges at the wall } & \multicolumn{2}{|c|}{ Mechanical condition at the wall } \\
\hline & & & H problem & HM problem & H problem & HM problem \\
\hline Drilling & -10 & 0 & & $p_{w}^{a i r}: 4.5 \rightarrow 0.1 \mathrm{MPa}$ & & $\sigma_{r}^{\Gamma}: \sigma_{r, i n i}^{\Gamma} \rightarrow 0.1 M P a$ \\
\hline Operation phase & 0 & 36 & \multirow{2}{*}{\multicolumn{2}{|c|}{$\begin{array}{l}p_{w}^{a i r} \text { imposed according to the air } \\
\text { relative humidity measured into the }\end{array}$}} & \multirow{3}{*}{\multicolumn{2}{|c|}{$\sigma_{r}^{\Gamma}=0.1 M P a$}} \\
\hline Concrete floor set up & 36 & 230 & & & & \\
\hline Airlock closed & 230 & 700 & & gallery & & \\
\hline
\end{tabular}

Table 4: Boundary conditions

7

\begin{tabular}{c|c|c|c|c}
\hline & & Undisturbed argillite & EDZ & Concrete \\
\hline$E$ & Young's modulus (MPa) & 4000 & 4000 & 30000 \\
\hline$v$ & Poisson's ratio (-) & 0.3 & 0.3 & 0.3 \\
\hline$C$ & Cohesion (MPa) & 3 & 3 & - \\
\hline$\varphi$ & Friction angle ( $\left.{ }^{\circ}\right)$ & 20 & 20 & - \\
\hline$b$ & Biot's coefficient (-) & 0.6 & 0.6 & 2300 \\
\hline$\rho$ & Density $\left(\mathrm{kg} / \mathrm{m}^{3}\right)$ & 2300 & 2300 & \\
\hline
\end{tabular}

Table 5: Mechanical parameters 


\begin{tabular}{c|c|c|c|c}
\hline & & Undisturbed argillite & EDZ & Concrete \\
\hline$K_{w, h o r}^{\text {sat }}$ & Horizontal water permeability $\left(\mathrm{m}^{2}\right)$ & $410^{-20}$ & $410^{-17}$ & $10^{-18}$ \\
\hline$K_{w, \text { vert }}^{\text {sat }}$ & Vertical water permeability $\left(\mathrm{m}^{2}\right)$ & $1.3310^{-20}$ & $1.3310^{-17}$ & $10^{-18}$ \\
\hline$\phi$ & Porosity (-) & 0.18 & 0.18 & 0.2 \\
\hline$\tau$ & Tortuosity (-) & 0.25 & 0.25 & 0.25 \\
\hline$P_{r}$ & van Genuchten air entry pressure (MPa) & 15 & 15 & 2 \\
\hline$n$ & van Genuchten parameter (-) & 1.49 & 1.49 & 1.54 \\
\hline$m$ & van Genuchten parameter (-) & 0.32886 & 0.32886 & 0.35065 \\
\hline
\end{tabular}

Table 6: Hydraulic parameters

3

\begin{tabular}{c|c|c}
\hline$K^{\text {pen }}$ & Penalty coefficient for seepage $\left(\mathrm{s} . \mathrm{kg}^{-1}\right)$ & $10^{-10}$ \\
\hline$\alpha$ & Mass transfer coefficient $\left(\mathrm{m} . \mathrm{s}^{-1}\right)$ & $10^{-5}$ \\
\hline
\end{tabular}

5

\begin{tabular}{c|c|c}
\hline & $\begin{array}{c}\text { Observations - Fractured } \\
\text { zone thickness (m) }\end{array}$ & $\begin{array}{c}\text { Numerical results -Plasticity } \\
\text { zone thickness (m) }\end{array}$ \\
\hline Horizontal & 0.5 & 0.4 \\
\hline Vertical (up) & 1.7 & 1.3 \\
\hline Vertical (down) & 2.0 & 1.7 \\
\hline
\end{tabular}

Table 8: $\overline{\text { Comparison between the thickness of observed fractured zone and numerical plasticity zone }}$

\begin{tabular}{c|c|c|c}
\hline & & Argillite & Injection interval \\
\hline$K_{w, h o r}^{\text {sat }}$ & Horizontal water permeability $\left(\mathrm{m}^{2}\right)$ & $410^{-20}$ & $10^{-12}$ \\
\hline$K_{w, v e r t}^{\text {sat }}$ & Vertical water permeability $\left(\mathrm{m}^{2}\right)$ & $1.3310^{-20}$ & $10^{-12}$ \\
\hline$K_{g, h o r}^{\text {dry }}$ & Horizontal gas permeability $\left(\mathrm{m}^{2}\right)$ & $310^{-18}$ & $10^{-12}$ \\
\hline
\end{tabular}




\begin{tabular}{c|c|c|c}
\hline$K_{g, \text { vert }}^{\text {dry }}$ & Vertical gas permeability $\left(\mathrm{m}^{2}\right)$ & $10^{-18}$ & $10^{-12}$ \\
\hline$\phi$ & Porosity (-) & 0.18 & 1 \\
\hline$\tau$ & Tortuosity (-) & 0.25 & 1 \\
\hline$P_{r}$ & van Genuchten air entry pressure (MPa) & 15 & 0.05 \\
\hline$n$ & van Genuchten parameter (-) & 1.49 & 1.5 \\
\hline$m$ & van Genuchten parameter (-) & 0.55 & 0.33 \\
\hline
\end{tabular}

Table 9: Hydraulic parameters

Figure 1 : Geometry of the SDZ experimental zone

6

Figure 4 : Time evolution of pore pressures in different sensors located (a) in borehole 2 (dip of $\left.45^{\circ}\right)$ and (b) in borehole 4 (horizontal and at the end of GED gallery)

Figure 5 : Time evolution of pore pressures in sensors located at (a) $4.5 \mathrm{~m}$ and (b) $6 \mathrm{~m}$ from the gallery wall for different boreholes orientations

Figure 6 : Schematic position of the pore pressure sensors (distances are measured from the gallery wall) Figure 7 : Gas flow injected experimentally at one face of the injection interval

Figure 8 : Time evolution of pore pressures in sensors before and during gas injection tests (a) Injection borehole - (b) and (c) Measuring borehole without and with zoom

Figure 9 : Experimental data for the retention curve of Callovo-Oxfordian argillite classed by (a) authors and (b) the drying or wetting path 
Figure 10 : (a) Experimental data for the water permeability evolution with the degree of saturation for Callovo-Oxfordian argillite - (b) Anisotropy effect on the water permeability of CallovoOxfordian argillite in saturated conditions (Pham, 2006; Semete et al., 2008; Boulin et al., 2008b; Hoxha \& Auvray, 2005; Homand et al., 2004; Escoffier et al., 2005; Heitz \& Hicher, 2002;

Koriche, 2004)

Figure 11 : (a) Experimental data for the gas permeability evolution with the degree of saturation- (b) Comparison between water permeability for saturated conditions and gas permeability for dried conditions for Callovo-Oxfordian argillite

Figure 12 : Two-dimensional finite element and boundary element

Figure 13 : Two-dimensional finite element and boundary element

Figure 14 : (a) Retention curve and (b) water permeability curve of Callovo-Oxfordian argillite: comparison between experimental data and relationships used in the modelling

Figure 15 : Comparison between experimental pore pressure (Full lines) and numerical water pressure

$$
\text { (Symbols) in boreholes (a) 1, (b) 2, (c) } 3 \text { and (d) } 5
$$

Figure 16 : Yield index at the end of the modelling (700 days) - Yield index = 1 : plastic domain - Yield index $<1$ : elastic domain

Figure 17 : Comparison between experimental pore pressure (Full lines) and numerical water pressure with imposed suction at the cavity wall (Symbols) in borehole 2

Figure 18 : Schematic view and geometry of the mesh and the outer boundaries

Figure 19 : Gas permeability curve of Callovo-Oxfordian argillite: comparison between experimental data and relationships used in the modelling

Figure 20 : Comparison between experimental and numerical pore pressure in interval 1 in the injection borehole for different initial water permeabilities and constant water compressibility $\chi_{w}=5 \mathbf{1 0}^{-10}$ $\mathbf{P a}^{-1}$ 
Figure 21 : Degree of saturation in the injection interval and in argillite at the end of the third injection $\operatorname{step}\left(261^{\text {th }}\right.$ day $)$

4

Figure 22 : Comparison between experimental and numerical pore pressure in interval 1 in the injection borehole for constant $\left(\chi_{w}=510^{-10} \mathrm{~Pa}^{-1}\right)$ or variable (with dissolved nitrogen concentration) water 7 compressibility

8

Figure 1: Geometry of the SDZ experimental zone

12

13
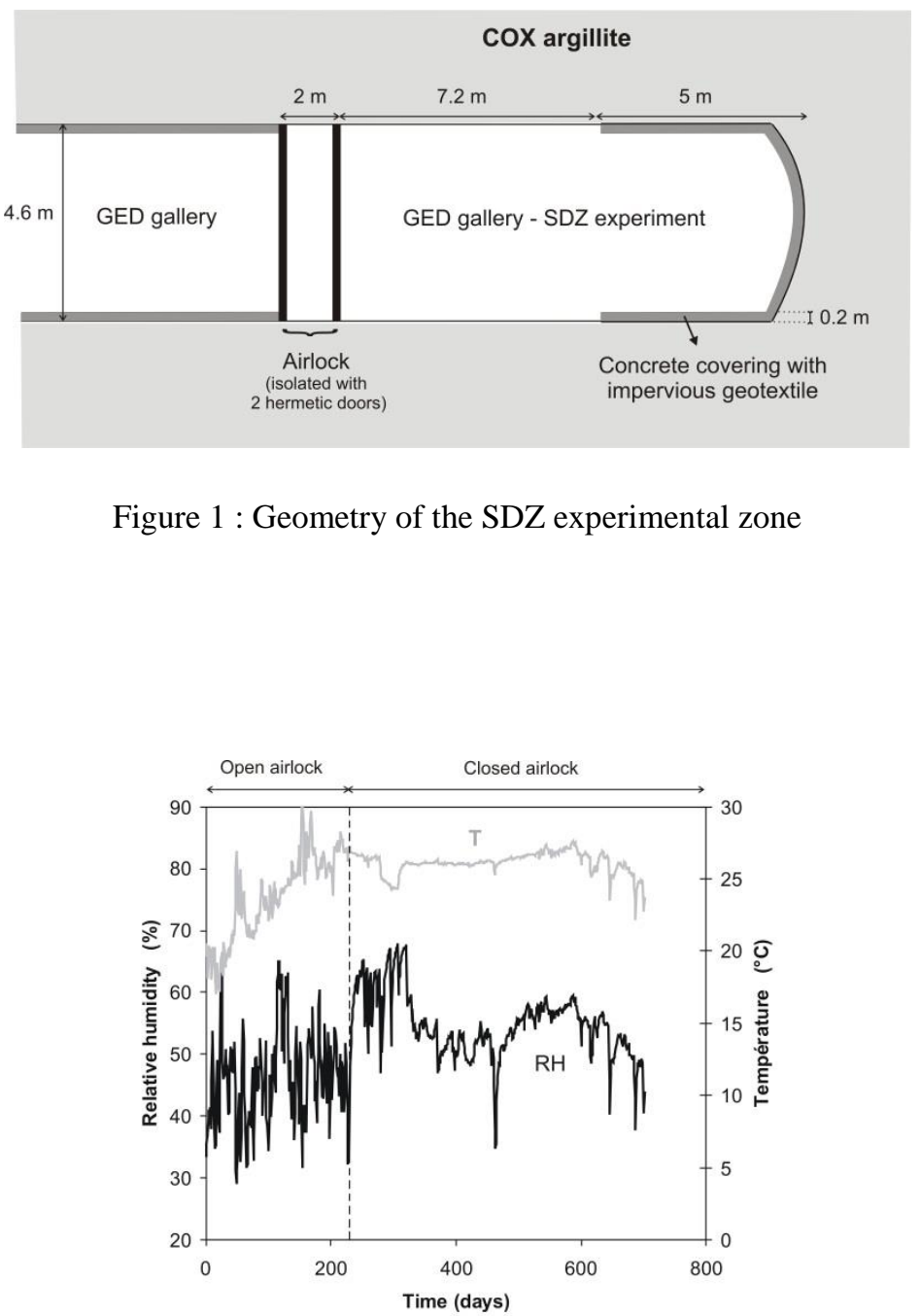


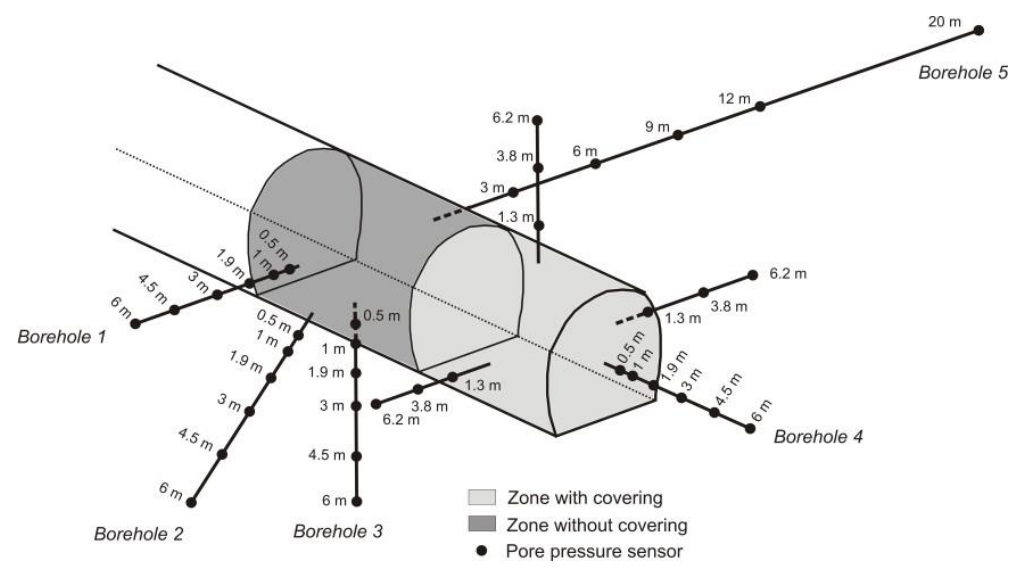

Figure 3 : Schematic position of the pore pressure sensors (distances are measured from the gallery wall)

3

4

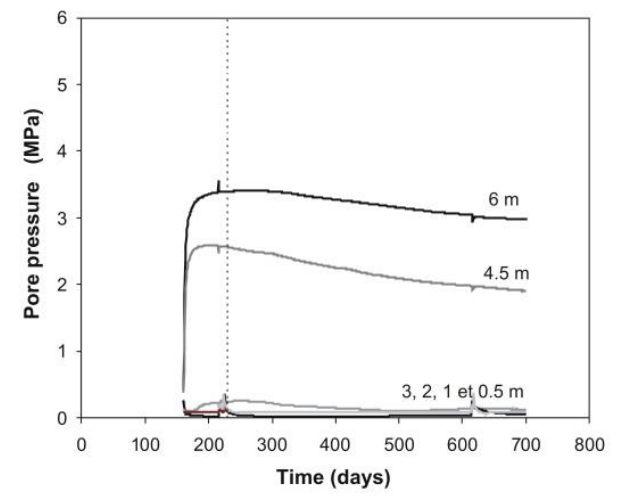

(a)

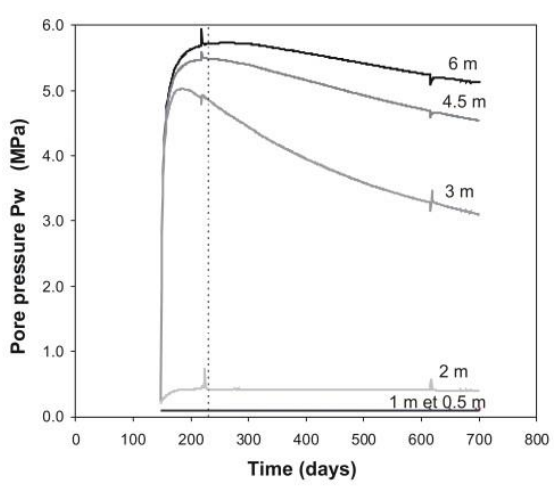

(b)

5 Figure 4 : Time evolution of pore pressures in different sensors located (a) in borehole 2 (dip of $45^{\circ}$ ) and (b) in borehole 4 (horizontal and at the end of GED gallery) 


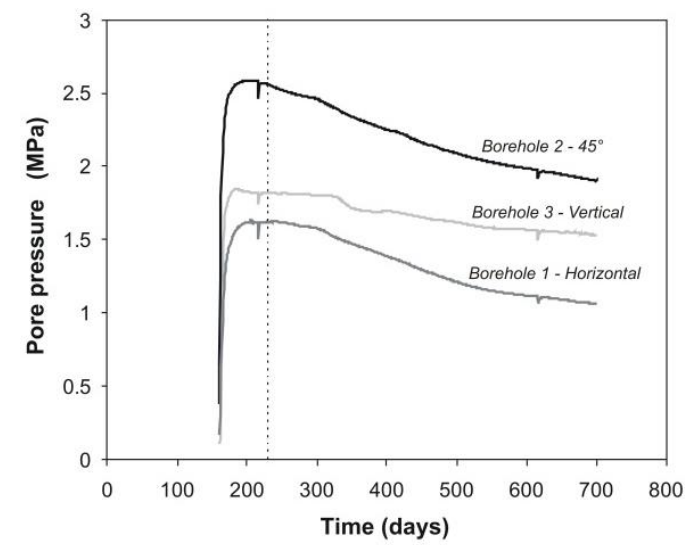

(a)

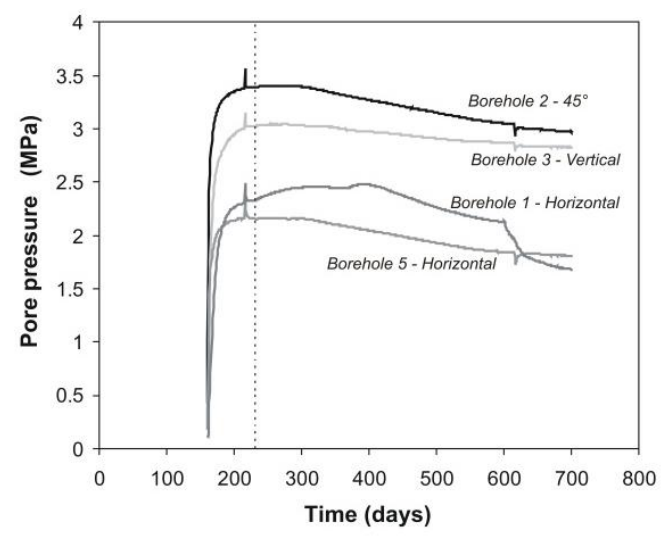

(b)

1 Figure 5 : Time evolution of pore pressures in sensors located at (a) $4.5 \mathrm{~m}$ and (b) $6 \mathrm{~m}$ from the gallery wall for different boreholes orientations

3
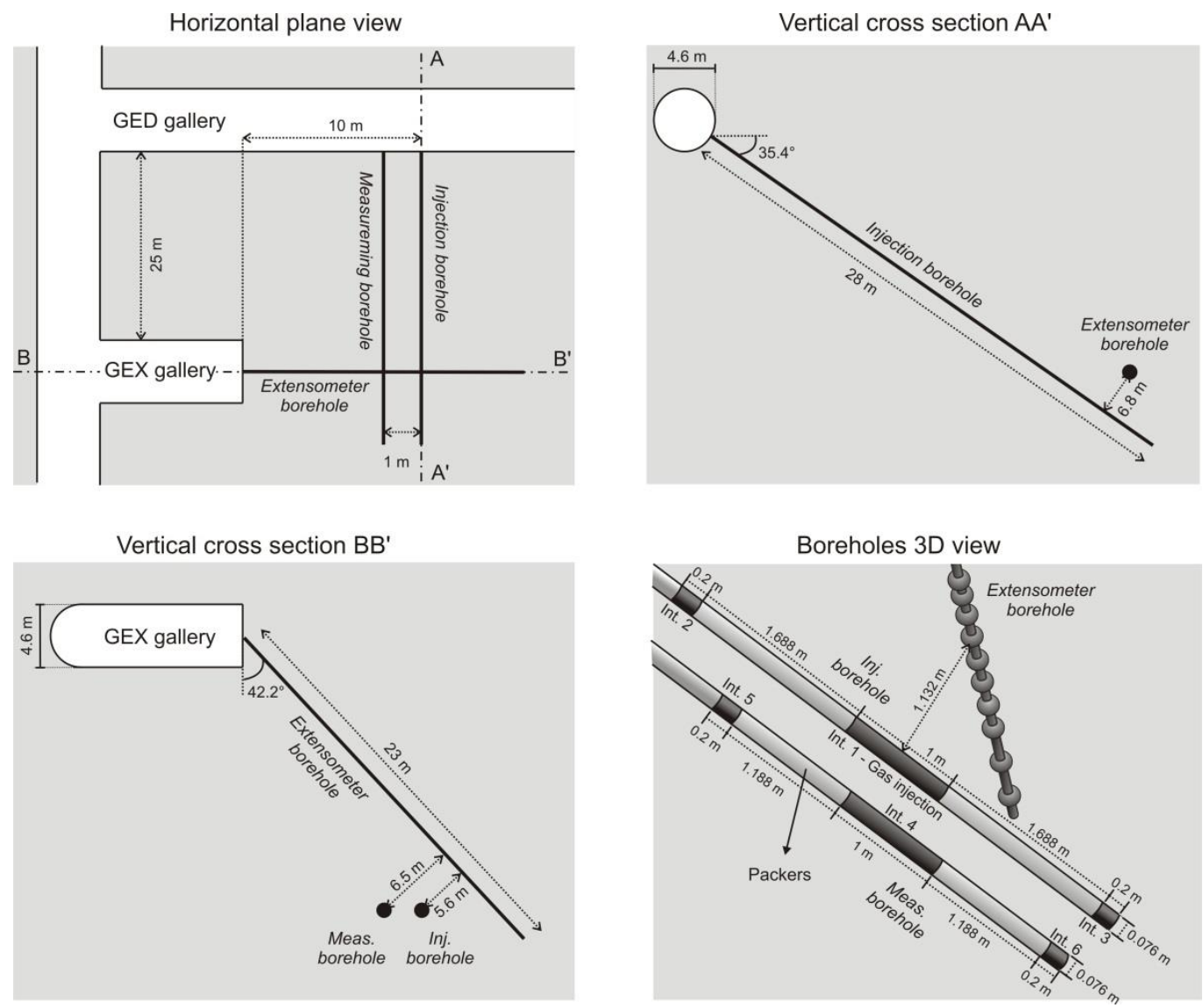

Figure 6 : Schematic position of the pore pressure sensors (distances are measured from the gallery wall) 

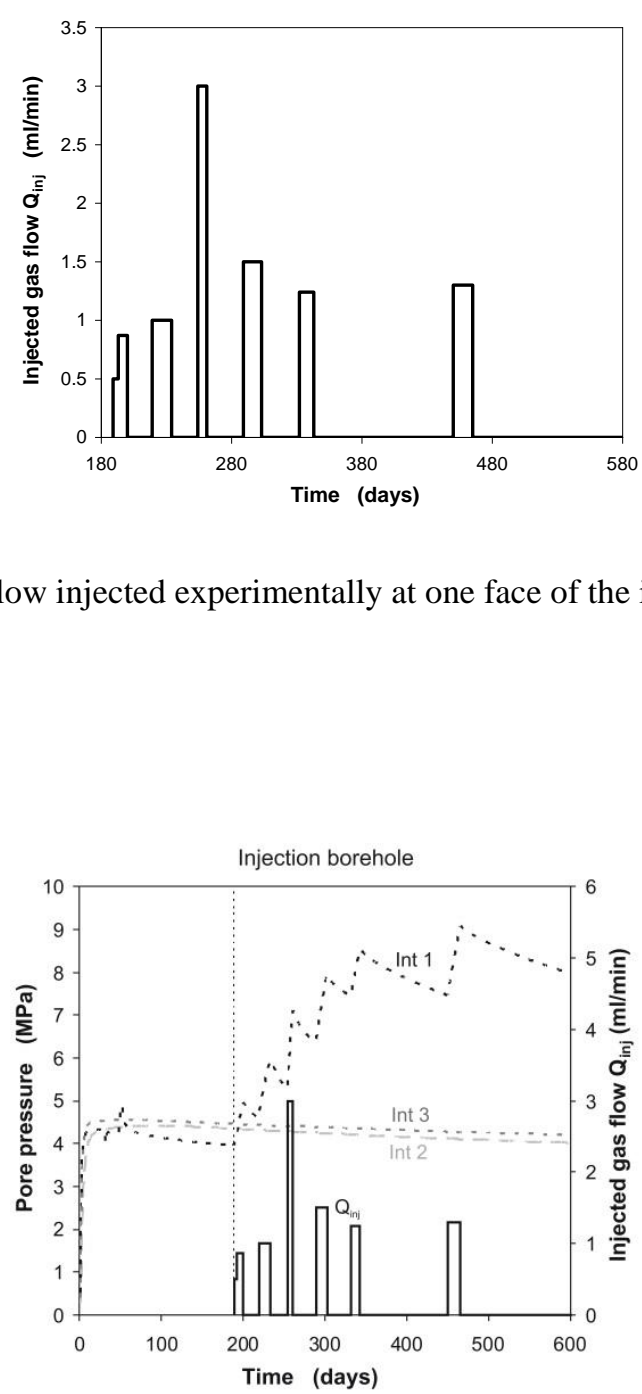

(a)

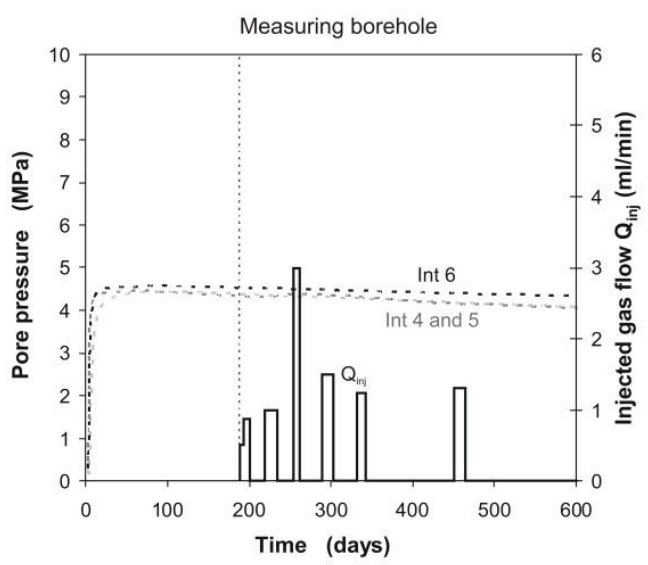

(b)

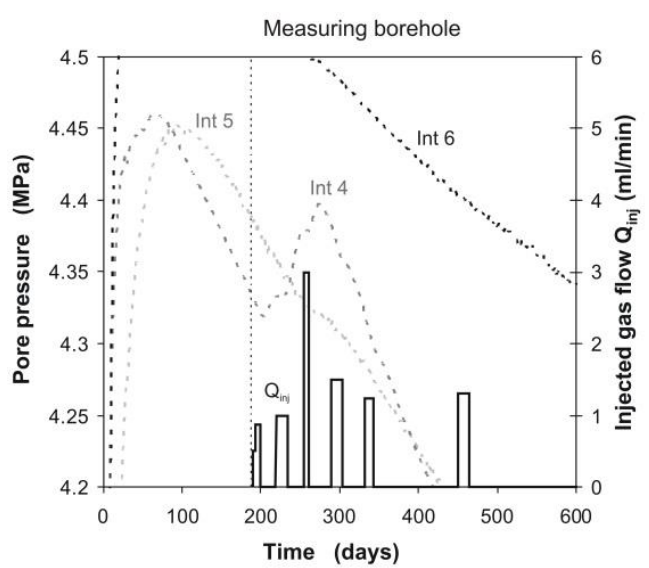

(c)

4 Figure 8 : Time evolution of pore pressures in sensors before and during gas injection tests (a) Injection borehole

- (b) and (c) Measuring borehole without and with zoom 


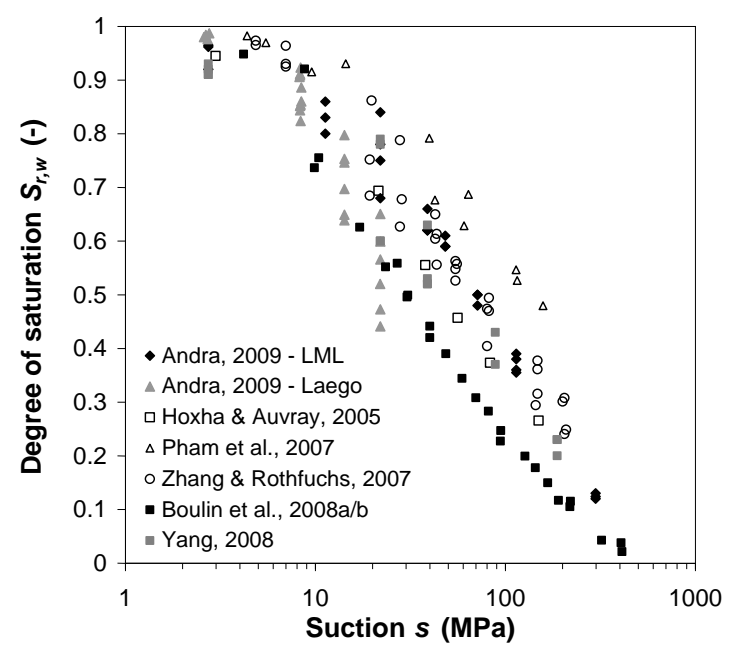

(a)

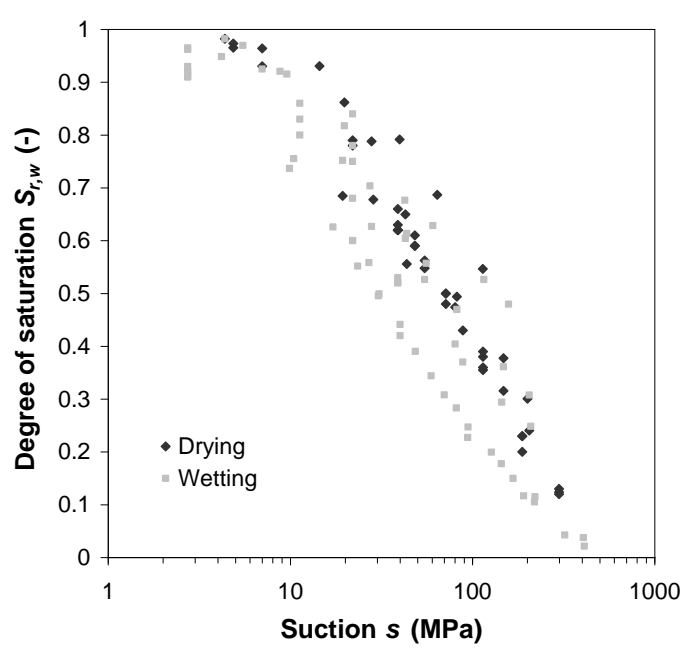

(b)

3 Figure 9 : Experimental data for the retention curve of Callovo-Oxfordian argillite classed by (a) authors and (b) the drying or wetting path

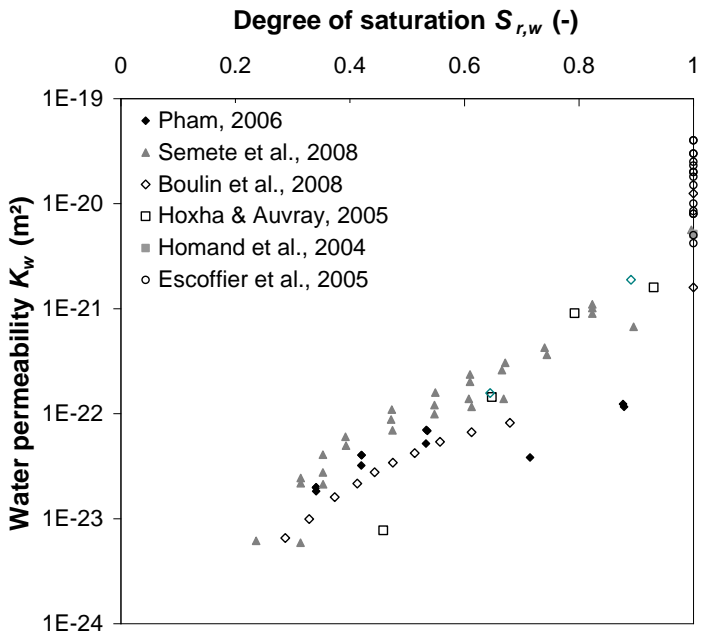

(a)

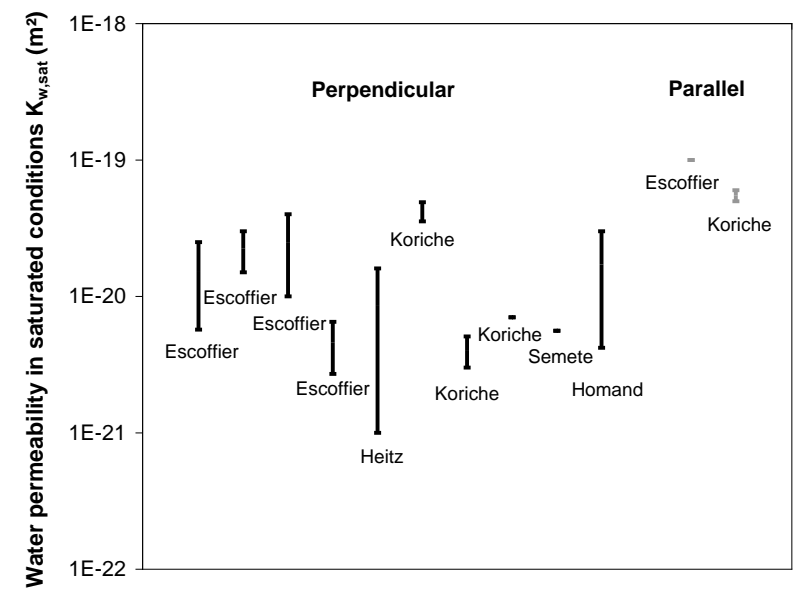

(b)

7 Figure 10 : (a) Experimental data for the water permeability evolution with the degree of saturation for CallovoOxfordian argillite - (b) Anisotropy effect on the water permeability of Callovo-Oxfordian argillite in saturated conditions (Pham, 2006; Semete et al., 2008; Boulin et al., 2008b; Hoxha \& Auvray, 2005; 


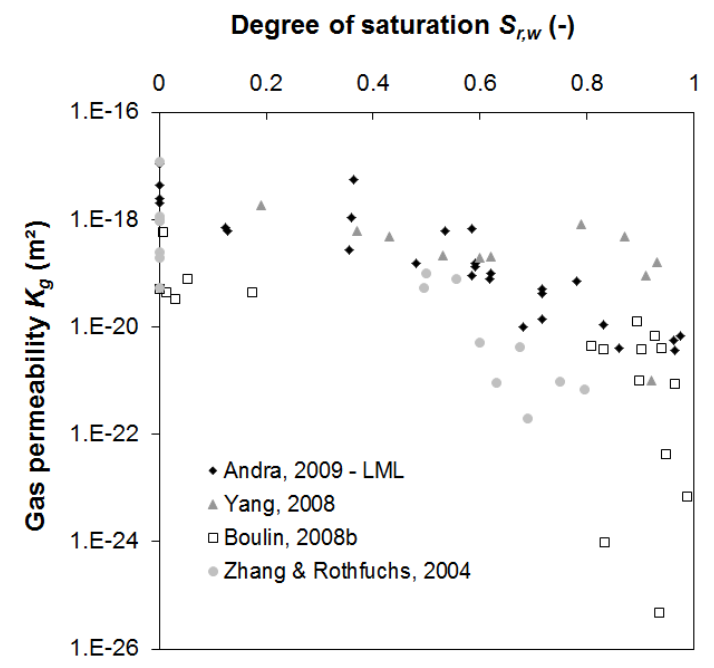

(a)

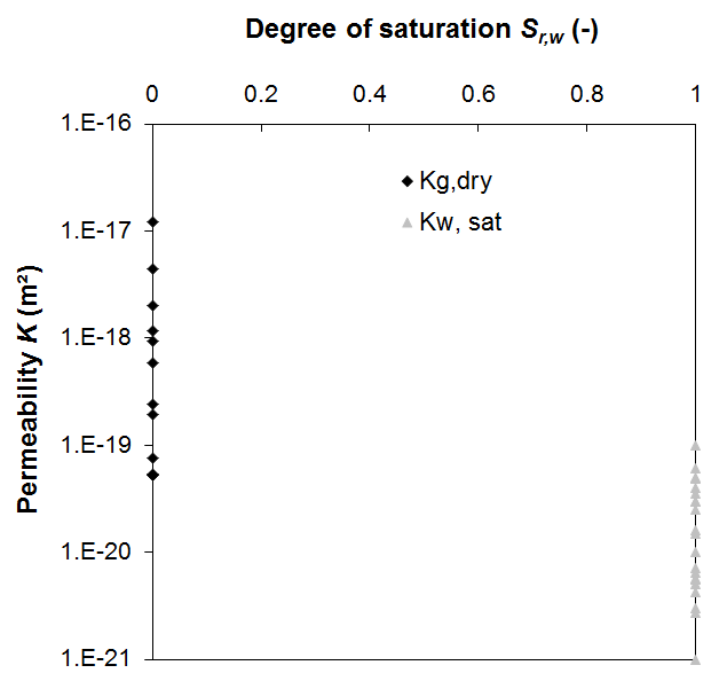

(b)

Figure 11 : (a) Experimental data for the gas permeability evolution with the degree of saturation- (b)

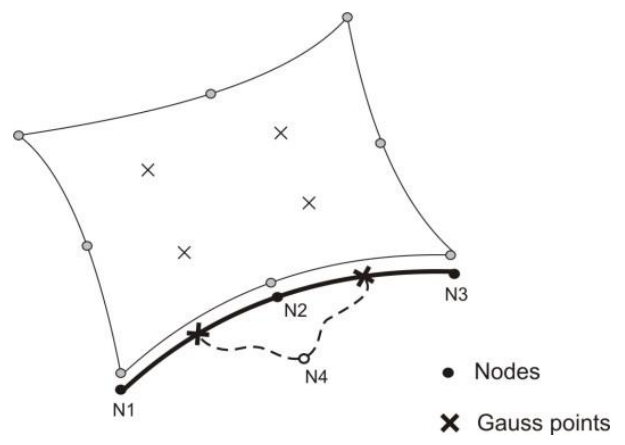



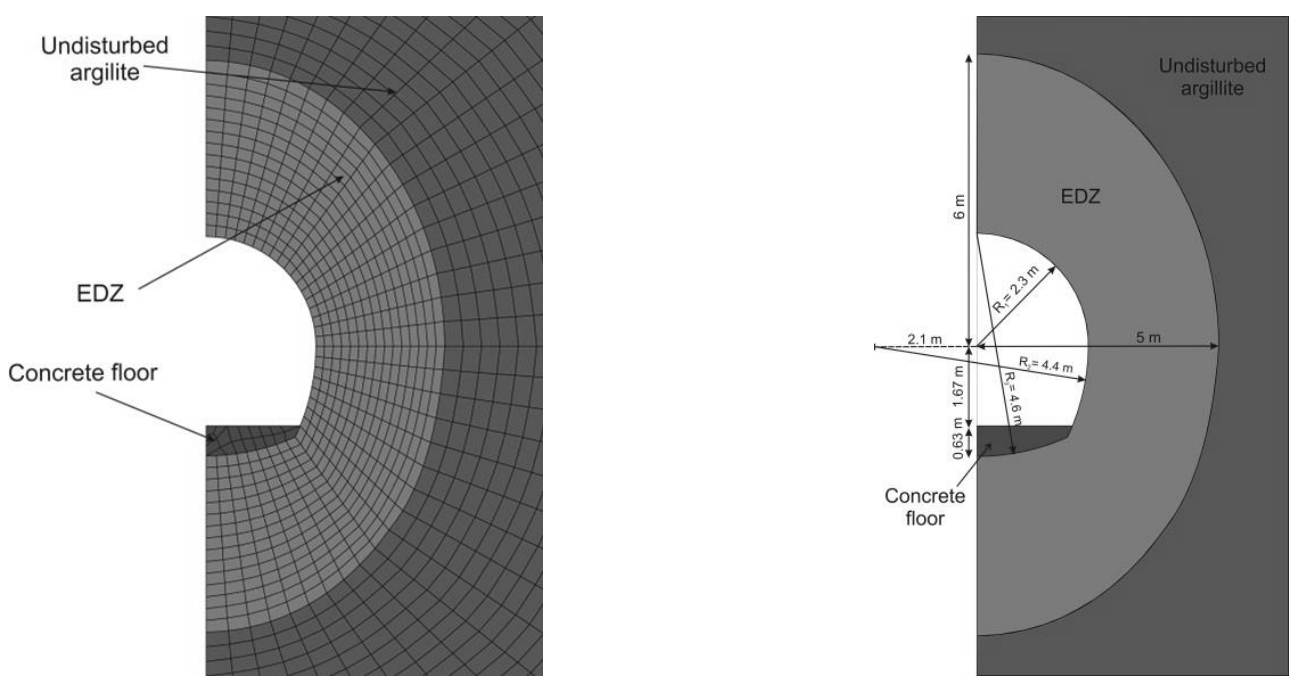

Figure 13 : Two-dimensional finite element and boundary element

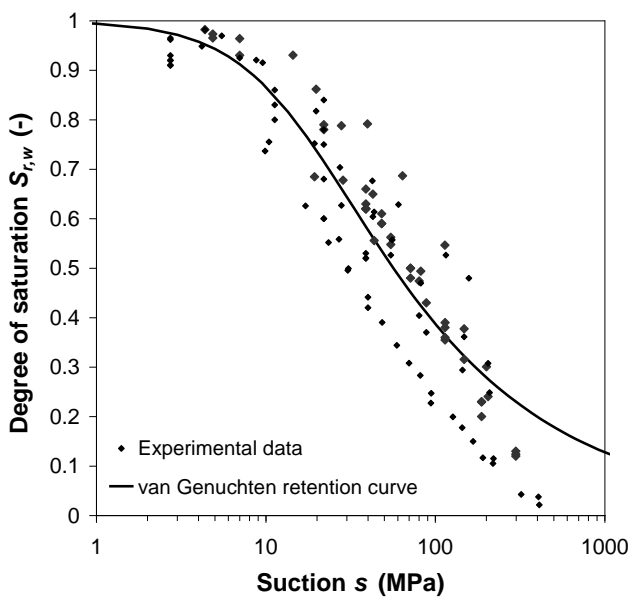

(a)

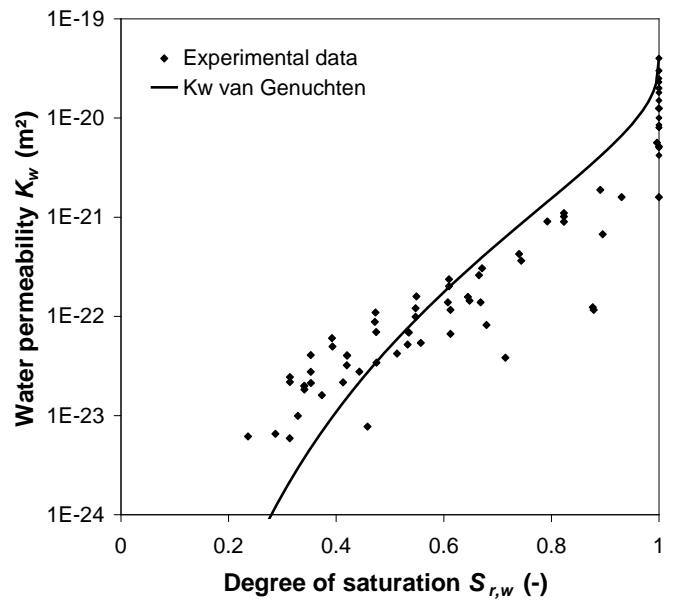

(b)

Figure 14 : (a) Retention curve and (b) water permeability curve of Callovo-Oxfordian argillite: comparison 


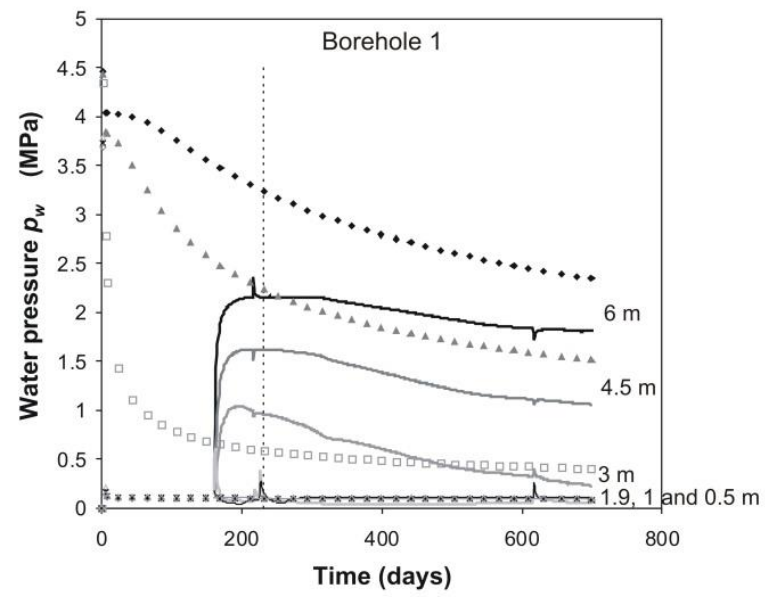

(a)

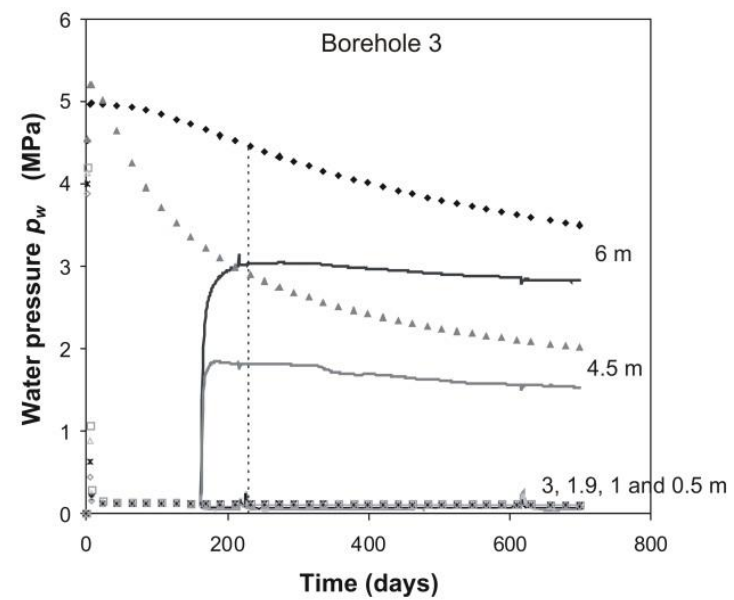

(c)

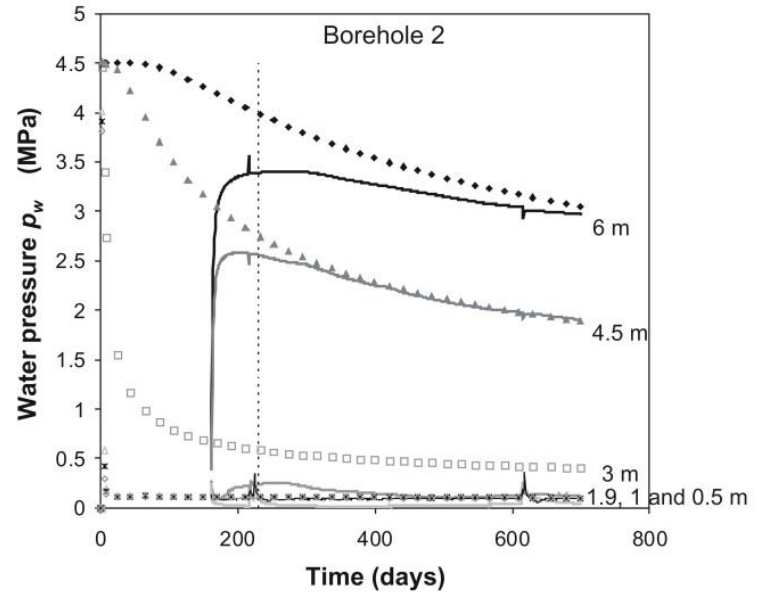

(b)

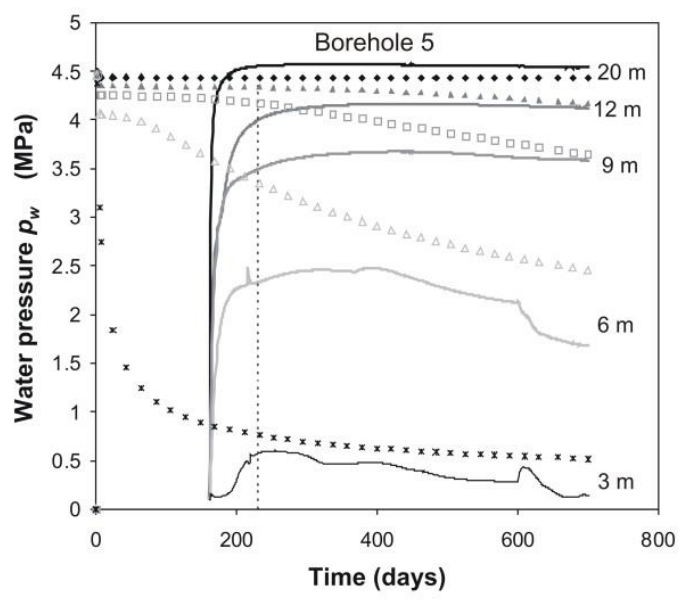

(d)

1 Figure 15 : Comparison between experimental pore pressure (Full lines) and numerical water pressure (Symbols) 


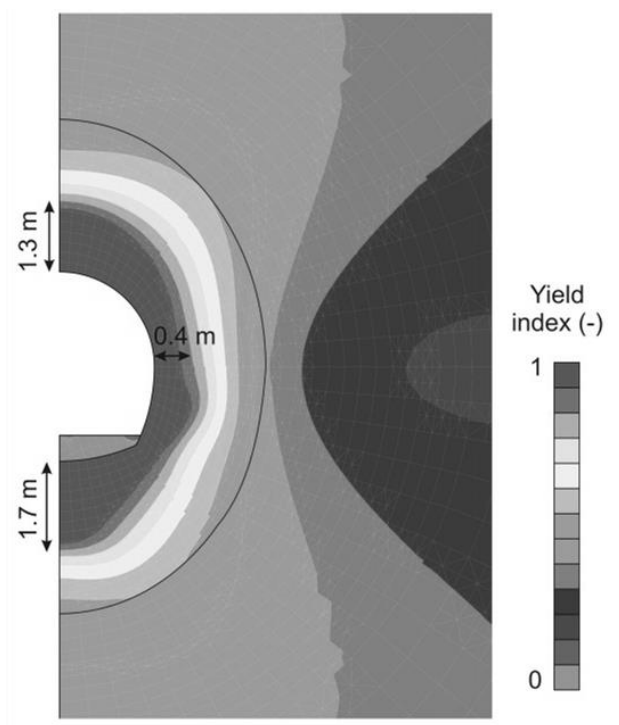

1 Figure 16 : Yield index at the end of the modelling (700 days) - Yield index $=1:$ plastic domain - Yield index $<$ 2 1 : elastic domain

3

4

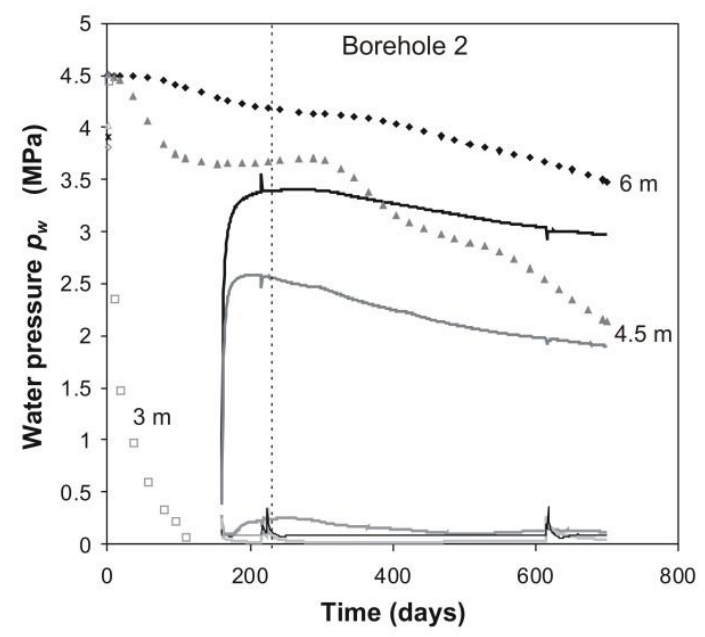

(a)

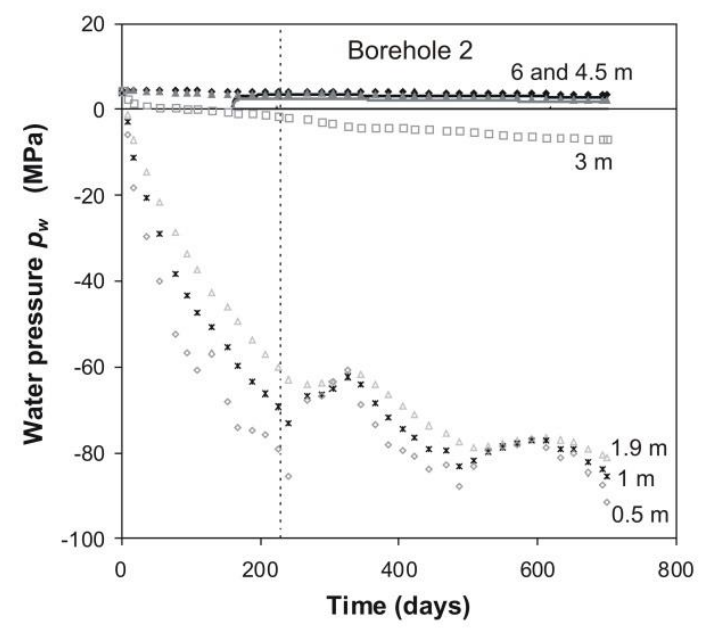

(b)

$5 \quad$ Figure 17 : Comparison between experimental pore pressure (Full lines) and numerical water pressure with imposed suction at the cavity wall (Symbols) in borehole 2 


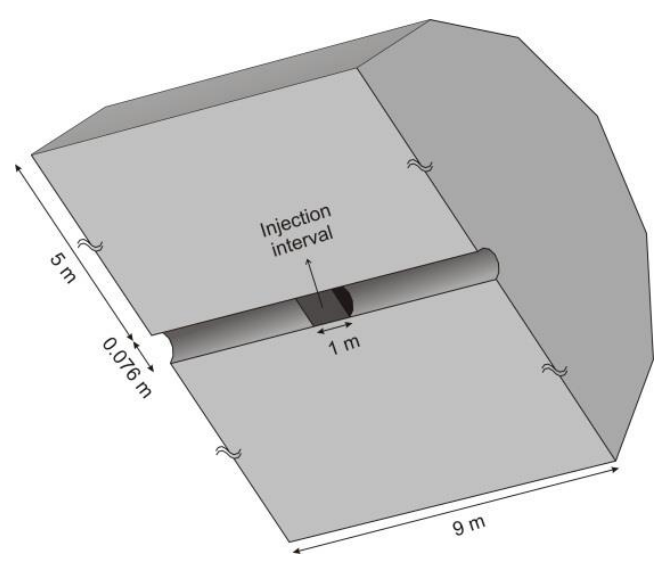

Figure $18:$ Schematic view and geometry of the mesh and the outer boundaries

2

3

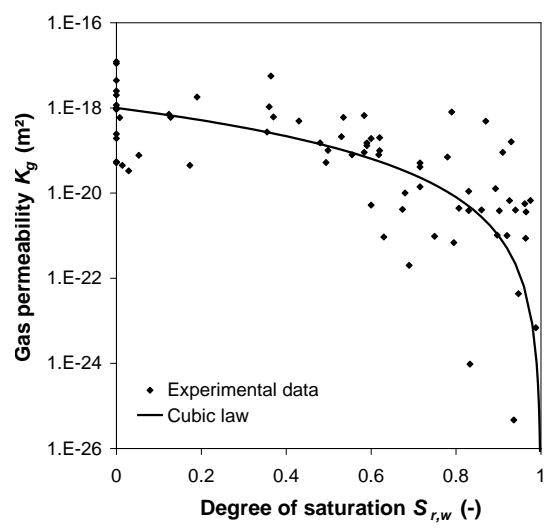

4 Figure 19: Gas permeability curve of Callovo-Oxfordian argillite: comparison between experimental data and 5 relationships used in the modelling

6

7 


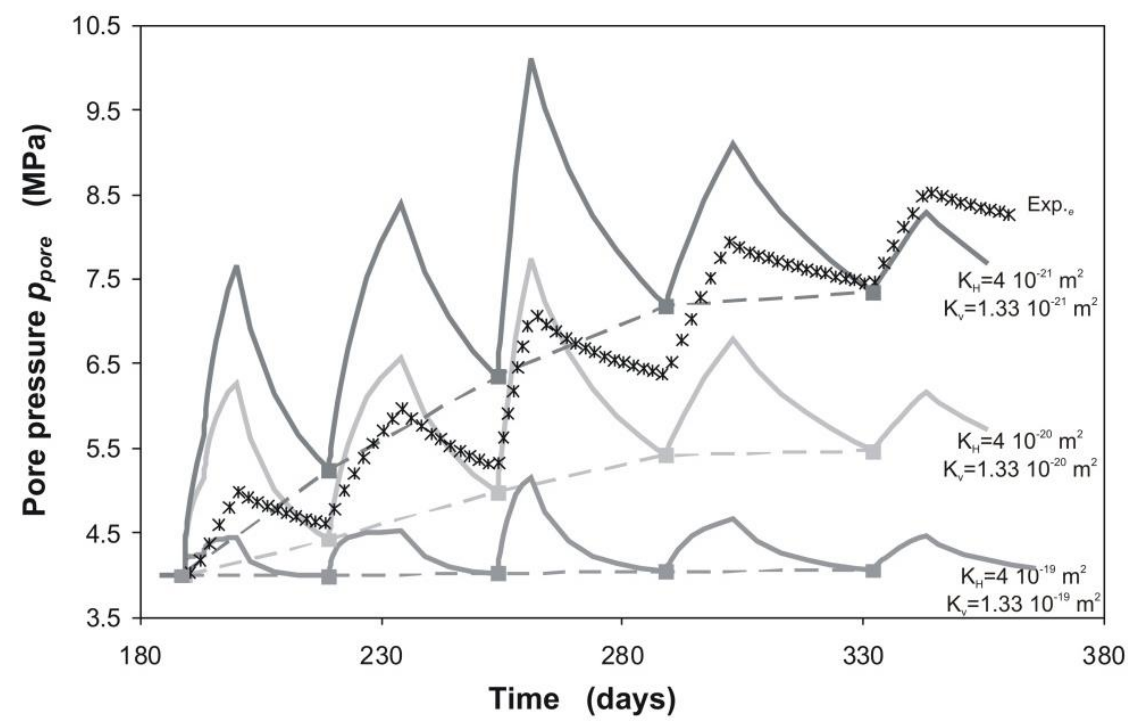

1 Figure 20 : Comparison between experimental and numerical pore pressure in interval 1 in the injection borehole for different initial water permeabilities and constant water compressibility $\chi_{w}=510^{-10} \mathrm{~Pa}^{-1}$

3

4

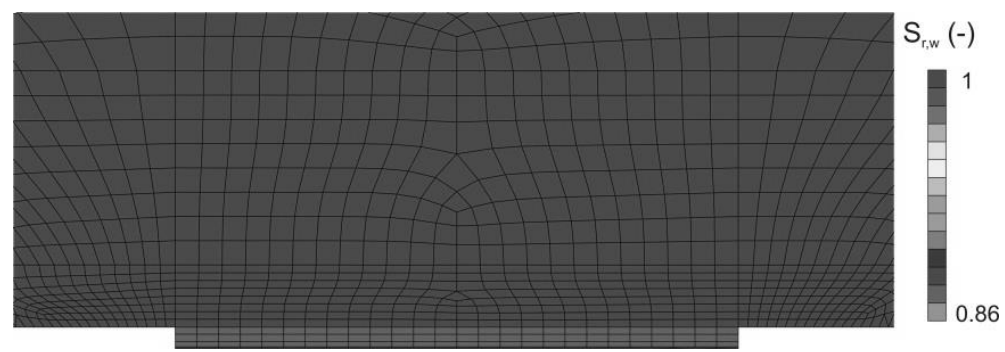

5 Figure 21: Degree of saturation in the injection interval and in argillite at the end of the third injection step 


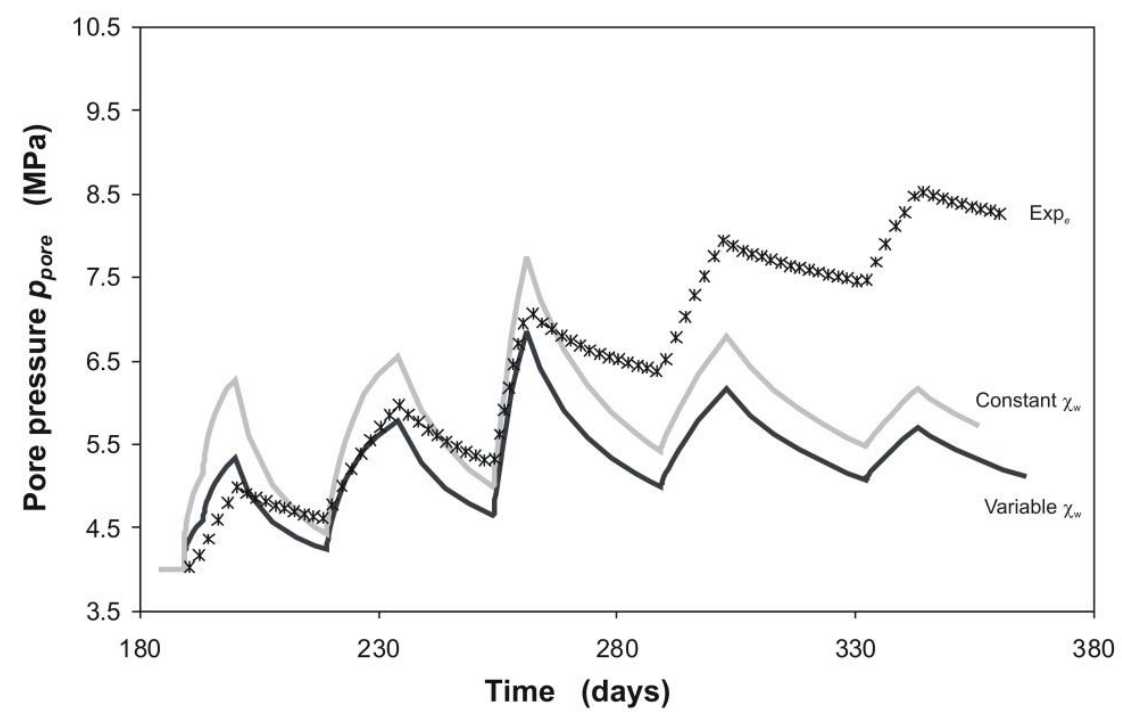

1 Figure 22 : Comparison between experimental and numerical pore pressure in interval 1 in the injection borehole for constant $\left(\chi_{w}=510^{-10} \mathrm{~Pa}^{-1}\right)$ or variable (with dissolved nitrogen concentration) water compressibility 